\section{Gamification in tourism and hospitality research in the era of digital platforms: a systematic literature review}

\author{
Maria Giovina Pasca, Maria Francesca Renzi, Laura Di Pietro and \\ Roberta Guglielmetti Mugion \\ Department of Business Studies, Roma Tre University, Roma, Italy
}

Gamification in tourism and hospitality

Received 8 May 2020 Revised 25 September 2020 12 March 2021 5 May 2021 Accepted 5 May 2021

\begin{abstract}
Purpose - The present study aims to synthesize and conceptualize, through a systematic literature review (SLR), the current state of gamification knowledge in the tourism and hospitality (T\&H) sector, providing a roadmap for future research recommendations for service research and practice.

Design/methodology/approach - The research is based on a systematic literature review and adopts a systematic quantitative approach to summarize existing evidence on gamification usage in the T\&H sector, focusing on relevant service literature on gamification. The authors analyze 36 papers published between 2011 and 2019 .

Findings - The authors synthesize existing knowledge into five themes describing gamification's role in T\&H (Edutainment, Sustainable behavior, Engagement factors, Service provider-generated content and Usergenerated reviews). Then, a cross-analysis of the five themes reveals the pivotal elements (affordances, behavioral and psychological outcomes, and benefits) generated by gamification mechanics in $\mathrm{T} \& \mathrm{H}$, simultaneously highlighting potential implications and relevant insights for service literature. The review identifies critical issues affecting gamification research and provides a future research agenda, considering opportunities for T\&H and service research.

Originality/value - The study provides the first SLR investigating gamification in T\&H. The findings present potential implications and relevant insights for T\&H contributing to the construction of a more holistic understanding of gamification adoption in service research.
\end{abstract}

Keywords Gamification, Tourism, Service research, Systematic literature review, Digital platform, Tourism and hospitality

Paper type Research paper

\section{Introduction}

The growth and diffusion of digital platforms, social media and mobile technologies have led to the rapid proliferation of the gamification phenomenon in service design (Deterding et al., 2011). Gamification has been applied in several non-gaming contexts (Robson et al., 2015; Deterding et al.,2011), and by companies seeking new tools to create a connection with users and influence and enhance the behavior of employees and customers (Baptista and Oliveira, 2017; Robson et al., 2015; Xu et al., 2016). Multiple studies reiterate that gamification is a persuasive strategy utilizing game-play mechanics (e.g. points, leader boards, achievements/ badges, levels, story/theme, clear goals, feedback, rewards), identified as affordances which change user behavior (Anagnostopolou et al., 2018; Hamari et al., 2014a). Indeed, these

(C) Maria Giovina Pasca, Maria Francesca Renzi, Laura Di Pietro and Roberta Guglielmetti Mugion. Published by Emerald Publishing Limited. This article is published under the Creative Commons Attribution (CCBY 4.0) licence. Anyone may reproduce, distribute, translate and create derivative works of this article (for both commercial and non-commercial purposes), subject to full attribution to the original publication and authors. The full terms of this licence may be seen at http://creativecommons. org/licences/by/4.0/legalcode

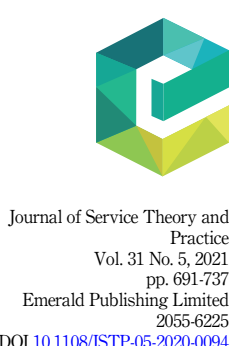

DOI 10.1108/JSTP-05-2020-0094 
JSTP 31,5

692

mechanics can generate psychological and behavioral outcomes (Koivisto and Hamari, 2019; Leclercq et al., 2018; Sigala, 2015a; Su and Cheng, 2015) and drive intrinsic motivation as well as relatedness, autonomy and competence (Sailer et al., 2017; Hamari et al., 2014b). Accordingly, to influence consumer engagement, loyalty, satisfaction and user experience, organizations operating in several contexts, including tourism and hospitality, have adopted gamification (Xu et al., 2013).

In recent years, the tourism and hospitality $(\mathrm{T} \& \mathrm{H})$ industry has rapidly evolved because of technological developments. The spread of ICT has contributed to the expansion of the sharing economy (Bernardi, 2015), changing the structure of the tourism market and influencing the demand for, and supply of, tourism products/services. Travel 2.0 enables the participation of consumers, allowing them to become co-creators of value by sharing information and co-distributors of tourism experiences and services (Sigala, 2007). The tourism industry can be described as a field providing services, characterized by experiences co-created with the active engagement of tourists (Vargo and Lush, 2008), service providers and platforms.

Gamification literature provides fragmented and contextualized research (Koivisto and Hamari, 2019). Hamari et al. (2014a) point out that the benefits of gamification, categorized as utilitarian, hedonic and social, depend not only on the users' perceptions and behavior but also on the context in which it is applied (Hammedi et al., 2017). In particular, as highlighted by Koivisto and Hamari (2019), the existing literature is primarily focused on the domains of education and learning, crowdsourcing and health, while any opportunities and benefits of its applications in other contexts need further research. The T\&H sector has relevant potentialities for applying gamification (Buhalis et al., 2019; Sigala, 2015a; Schuckert et al., 2015). Gamified applications create opportunities for interaction with the tourist destination (Aebli, 2019) and transmitting knowledge (Lee, 2019). An example of gamification widely adopted in the T\&H sector is the frequent player program (Xu et al., 2013), which is a means of collecting points that can be exchanged for bonuses or rewards (Seaborn and Fels, 2015). Further gamification applications aim to increase the involvement of tourists and employees in behavioral change (such as product purchases or efficient work), generating intrinsic motivation and co-creating value (Huotari and Hamari, 2017). Airbnb, for instance, adopts badges to guide users on how to use the service, to improve the quality of the service offered, and to create trust between hosts and guests (Hamari and Eranti, 2011; Jakobsson, 2011; Resnick and Zeckhauser, 2002). Motivation, engagement, loyalty and brand awareness are crucial aspects for users. Therefore, as the T\&H sector is user-centric, the application of gamification is useful and strategic. Co-created customizable experiences/services (Pine and Gilmore, 1999) by both service providers and tourists bring enjoyment, fun and social connection (Lee, 2019; Neuhofer et al., 2012). Moreover, Rapp et al. (2018) note that gamification seems to be particularly suitable for application in contexts involving shortterm interaction between users and platforms. This corresponds to the T\&H context, where users' experiences are confined to a specific time frame starting with the pre-visit, continuing with the visit and ending with the post-visit.

In addition, Buhalis et al. (2019) and Phillips and Moutinho (2014) invite us to consider $\mathrm{T} \& \mathrm{H}$ as a frontline service industry which integrates technological advancements in strategic processes. Therefore, it is vital to investigate how gamification, especially if mediated by digital platforms, can contribute to innovate the T\&H sector, and to study the potentialities and impact of this phenomenon for all the sector's actors, such as consumers, service providers, digital platform providers and communities. In this regard, to encourage and guide future research, our study proposes an SLR that summarizes existing studies, highlights the potential and limitations of this tool, and provides a roadmap for future research in both the T\&H and service fields. Indeed, as stated by Donthu et al. (2021), a current 
service research challenge is to investigate how emerging technologies are used Gamification in collaboratively and the implications for services.

Considering the potential significance of gamification in the service field, the present study provides a rigorous analysis able to synthesize and conceptualize the current state of gamification knowledge in the T\&H sector (Heinonen et al., 2018), focusing attention on relevant service research literature and contributing to the construction of a more holistic understanding of gamification adoption in the service sector. In addition, no SLRs on gamification adoption in T\&H sector have been carried out so far.

In light of this, the present study attempts to fulfil a triple aim: (1) to synthesize the findings of extant research published in leading business and service-oriented journals (Lu et al., 2020) on gamification adoption in the T\&H industry (the motivations, benefits and obstacles, opportunities and critical issues); (2) to identify themes, research gaps and priorities; and (3) to provide direction through a future research agenda, thus enabling both scholars and practitioners to study and implement gamification in the T\&H sector and, more generally, in service research.

Our study is organized as follows. Section 2 describes and explains the gamification in the tourism industry. Section 3 illustrates the research methodology. Section 4 provides the main results of the review, identifying bibliometric characteristics, key themes and, for each theme, presenting affordances, outcomes, benefits and results. Section 5 presents a cross-discussion of the identified themes analyzing the pivotal elements of gamification and the main critical issues affecting gamification application in T\&H and service science. Section 6 illustrates recommendations for further research. Section 7 concludes the work and examines the limitations of our review.

\section{Background}

\subsection{Gamification}

Since 2011 there has been a significantly increased interest in the topic of gamification among academics and practitioners (Hamari et al., 2014a). Gamification has been adopted in different contexts and is a booming market. In 2018, the global gamification market was valued at $\$ 6.8$ billion and an increase to $\$ 40$ billion is expected by 2024 (Reportlinker, 2018).

The phenomenon of gamification represents a major development in the information systems field and has been applied in several contexts such as crowdsourcing (Lee et al., 2013; Ipeirotis and Gabrilovich, 2014; Morschheuser et al., 2016), commerce (Hamari and Koivisto, 2015), health (Jones et al., 2014; Alahäivälä and Oinas-Kukkonen, 2016), education (Bonde et al., 2014; Christy and Fox, 2014; Majuri et al., 2018), environmental behavior (Lee et al., 2013; Lounis et al., 2014), and marketing and advertising (Terlutter and Capella, 2013; Xi and Hamari, 2019).

Huotari and Hamari (2012, p. 23) define gamification as a service packaging which enhances customers' value creation, namely "a process of enhancing a service with affordances for gameful experiences in order to support the user's overall value creation." The peculiarity of the gamification phenomenon is that the game experience is moved outside the natural gaming context (Xu et al., 2017; Zichermann and Cunningham, 2011). In the field of management it is intended to orchestrate processes and services that push users to co-create in the achievement of organizational goals through the provision of positive experiences (Deterding, 2019). As stated by Wünderlich et al. (2020), thanks to the adoption of gamification dynamics, organizations can increase customers' commitment and loyalty, willingness to pay, and referral behavior, as well as enhance the engagement of other stakeholders, such as employees.

Both the aim of gamification, and its effectiveness, are grounded in the desire to motivate and guide users' behavior towards a specific goal, by engaging them through the application of game mechanics and dynamics (Sigala et al., 2019; Sigala, 2015a). Several authors 
JSTP 31,5

694

(Deterding, 2015; Hamari et al., 2014b; Huotari and Hamari, 2017; Sigala, 2015a) in conceptualizing gamification, identify three main, interconnected elements, namely: affordances, psychological and behavioral outcomes. The affordances are the mechanics and hidden rules at the root of the game structure which engage users with a specific system. These game mechanics impact the users' psychology, generating involvement, knowledge, flow, and social recognition or enjoyment. User involvement through game mechanics leads to psychological outcomes related to the motivations of the game, and the attitude and enjoyment of users (Cheong et al., 2013; Dominguez et al., 2013). Behavioral outcomes refer to behaviors and activities that are supported through the use of gamification, such as the performance and use of the system. The affordances can create positive psychological outcomes that in turn lead to behavioral outcomes (e.g. increased user participation in the desired game/activity) and value creation (Hamari, 2013). The benefits generated by gamification have been categorized as utilitarian (i.e. usefulness and ease of use), hedonic (i.e. enjoyment and playfulness) and social (i.e. recognition and social influence) (Hamari and Koivisto, 2015). The purpose of gamification mechanics is to stimulate engagement and improve the experience (Deterding et al., 2011).

Using the lens of the self-determination theory (Deci and Ryan, 1985) to understand the motivational potential of gamification mechanics, it is possible to categorize motivation as extrinsic and intrinsic. The former includes activities that are carried out to obtain results in the form of rewards (Ryan and Deci, 2000a). In this case, the decision to play is guided by rewards, such as money, prizes, recognition and status (Zichermann and Cunningham, 2011). The latter, instead, depends on the specific needs and interests of each user, namely satisfaction, gratification, the need to socialize, and the desire to establish oneself in a community (Swacha and Ittermann, 2017). Users engage more in an activity when they are intrinsically motivated. Users' well-being and motivation derive from the satisfaction of three needs: autonomy, competence and relationship (Ryan and Deci, 2011), which affect the enjoyment and engagement of users (Ritcher et al., 2015; Suh et al., 2015). Players are completely immersed in the virtual world and this flow contributes to their enjoyment and satisfaction, generating well-being behaviors (Mulcahy et al., 2018). It is crucial to design gamified applications that take into account the characteristics of users (Xu et al., 2017). Moreover, as pointed out by Sigala (2015b), the use of extrinsic rewards can have negative effects on users' motivation if they find themselves having to perform difficult tasks with respect to their level of knowledge. Intensely motivated users fall into a "flow state" that favors their engagement, leading them to focused concentration and loss of self-awareness (Sigala, 2015a).

In some instances, alternative terms such as "serious games" (Bogost, 2007; Kapp, 2012) are used to inaccurately refer to the phenomenon of "gamification", generating confusion about the terms and their meanings both in theory and practice (Xu et al., 2017; Johnson et al., 2016; Kapp, 2012; Seaborn and Fels, 2015). Nevertheless, both are grounded in the engaging nature of recreational digital games with a view to enabling behavioral change. A serious game is defined as "any form of interactive computer-based game software for one or multiple players to be used on any platform and that has been developed with the intention to be more than entertainment" (Ritterfeld et al., 2009, p. 6). Thus, serious games are full-fledged games in which the fantasy world is combined with reality (Seaborn and Fels, 2015) to influence and educate the players, increasing their knowledge and skills (Susi et al., 2007). They include pedagogical aspects (Zyda, 2005) and, because of this, they are defined as "games for serious purpose" (Fleming et al., 2017). In contrast, "gamification" refers to the application of game dynamics in a non-game setting. In the gamification context, the games "are deliberately designed to afford positive experiences" (Deterding, 2019, p. 133). 


\subsection{Gamification in the tourism industry}

The tourism sector has been revolutionized in recent decades by technological innovation. The spread of ICT has changed the structure of the tourism market, influencing both the demand for and the supply of tourism services. Digital platforms have changed the roles of providers and consumers, increasing and improving the variety of services and experiences, and revolutionizing how companies and consumers interact (Tobon et al., 2020). Tourist experiences are co-created by tourists and service providers through technology (Tussyadiah and Fesenmaier, 2009; Neuhofer et al., 2012; Vargo and Lush, 2008) and digital platforms. Accordingly, platform providers have expanded their role, and their business has rapidly scaled up in the last decade. Moreover, the preferences and needs of the "new tourist" favor the use of digital platforms and the development of the sharing economy, allowing extension beyond the experiences and standardized and impersonal services often associated with the traditional tourism system (Paulauskaite et al., 2017).

Enjoyment and ease of use are determinants for the continued use of gamification services (Xu et al., 2016). Hamari and Koivisto (2015) have shown that users are motivated to use gamification for hedonic aspects, while utilitarian and social factors influence attitudes toward the systems which, in turn, affect intentions of use. When the use of the system is voluntary, the user is influenced by the opinions of other users and wishes to feel part of the community (Kelman, 1958; Venkatesh and Davis, 2000). These elements confirm that gamification is particularly suitable for application in the T\&H industry where aspects such as enjoyment, curiosity and socializing are key drivers for tourist satisfaction.

In the $\mathrm{T} \& \mathrm{H}$ sector, nowadays we can identify different actors involved in gamified mechanics: tourists, service providers and platform providers. Thus, the resulting new service ecosystem is a context with potential for applying gamification (Sigala, 2015a). From a user perspective, gamification usage depends on utilitarian and hedonic motivations. Indeed, curiosity, enjoyment and socializing are the main motivations for tourists, together with having pleasurable experiences and fulfilling challenges and achievements.

The concept of gamification has its roots in customer loyalty or rewards programs (e.g. subscriptions and points cards), where consumers obtain points to redeem for products (Zichermann and Linder, 2010). Tourists look for unique and memorable experiences (AguiarCastillo et al., 2019), and the strategic use of ICT and the diffusion of digital platforms contributes to generating engagement and creating value for the company and for tourists (Breidbach and Brodie, 2017). In the context of T\&H, digital platforms have consumeroriented technologies (Guerreiro and Moro, 2017; Moro et al., 2018), and gamification affordances have been implemented to attract users and increase their engagement. Nowadays, the gamified tourism apps can stand out with games that promote and provide tourist information about the visit, and location-based games that aim to increase engagement with the exploration of the place (Bartoli et al., 2018; Deterding et al., 2011; Xu et al.,2015). The use of gamification involves tourists through imagination and enjoyment, enhancing tourists' experiences by "getting tourists immersed into a simulated travel world," with emotional and more engrossing experiences (Xu, 2011; Sigala, 2015b, p. 202). This tool can change behavior and influence psychological needs by integrating fun, dynamism and involvement in order to improve customer loyalty (Xu et al., 2017). Gamification allows tourists to co-create experiences by generating positive emotions (e.g. well-being) and engagement by leveraging psychological needs: autonomy, competence and relatedness, such as the desire to be part of the community (Aebli, 2019). Moreover, gamified mechanics encourage tourists to use digital platforms by generating content (e.g. reviews), or by motivating them through badges. Correspondingly, they co-create value by improving the providers' service performances and guaranteeing the quality of the service offered.

Moreover, from the service provider perspective, gamification contributes to employees' training (Xu et al., 2014, 2017) and allows to educate consumers (Hamari, 2013). Through
Gamification in tourism and hospitality 
JSTP 31,5

696

gamification, tourist companies create fun and engaging tourist experiences, generating satisfaction and profit while helping to increase customer loyalty (Xu et al., 2015). Despite the potential benefits, the adoption of gamification among tourism service providers is very limited (Buhalis and Wagner, 2013). It has emerged that tourist providers face challenges in planning initiatives/services that are gamified due to the cost of the projects and the difficulties in measuring their results (Kiralova, 2015). However, tourism service providers must constantly strive to enhance the tourist experience. For instance, the Airbnb platform guides the behavior of hosts (service providers) and creates a relationship of trust between hosts and guests through gamification mechanics, that is, providing badges and points to hosts when they provide quality services (Resnick and Zeckhauser, 2002). In fact, the "Superhost" program aims to create incentives that guarantee the involvement of the hosts and the improvement of the service quality (Liang et al., 2017), satisfying the needs of guests (Hamari and Eranti, 2011; Jakobsson, 2011). The purpose of the badge is to ensure that hosts are committed to providing performance that meets high service standards (Liang et al., 2017).

All these dynamics are possible thanks to the growing diffusion of ICT systems which has favored the distribution and integration of the game elements (Brigham, 2015; Kapp, 2013) on digital platforms. With this tool, tourism companies improve the engagement during visiting experience and their knowledge of the destination by making them more aware of local resources (Lim et al., 2015; de Oliveira Nunes and Mayer, 2014). The implementation of game mechanics on digital platforms allows the attraction and retention of more platform visitors and makes a large amount of data on tourists' preferences, perceptions, feedback and visit paths available to service providers (Sigala, 2015a). Service providers are motivated to participate to retain tourists (Werbach and Hunter, 2012), who are engaged with the destination (Aebli, 2019) by receiving information about the tourist site (Lee, 2019).

Sigala (2015a) highlights several motivations that influence users to use gamified applications such as the desire for relationship, friendship and support among members of the social community. Other elements which contribute to users being engaged in gamified mechanics include: the desire to be immersed and escape into a fantasy world; the desire for pain, using other players for their own goals by killing or deceiving others; the desire for success and power, by reaching the objectives defined by the game; the desire for leadership; and the desire to live a shared experience, by feeling part of a community of players and acquiring a reputation within it.

It emerged that the literature confirms the relevance of gamification in $\mathrm{T} \& \mathrm{H}$, and as far as we know no SLRs on this topic have been developed. Accordingly, the present research aims to summarize gamification knowledge in the $\mathrm{T} \& \mathrm{H}$ sector, in order to provide useful insights for service research and practice.

\section{Methodology}

\subsection{Systematic literature review}

Relevant studies (Sigala, 2015a; Schuckert et al., 2015; Buhalis et al., 2019; Aebli, 2019; Lee, 2019) emphasize the potential deriving from gamification adoption in the T\&H industry. As noted by Xu et al. (2017), tourists are increasingly looking for unique experiences that involve multisensory involvement and stimulation. It has become a priority to deepen analysis of the contribution that gamification can make to the T\&H sector. Accordingly, by identifying and analyzing the existing literature concerning this topic, this paper contributes to understanding how the phenomenon has been received so far. Simultaneously, it underlines what is unknown and/or uncertain, providing useful directions for future research.

As recognized by Snyder (2019), generally a literature review allows the synthesis of existing research and evidence, detecting and uncovering areas for extensive studies. 
The SLR is a robust, repeatable and transparent scientific method adopted in the wider social sciences (Tranfield et al., 2003), including in the T\&H sector (Ip et al., 2011; Mariani et al., 2018; Yang et al., 2017). In line with the concepts of MacInnis (2011), the present SLR aims for "summarization": namely, to "take empirical evidence into account to derive conclusions about what is known" (p. 144), by narrowing "many empirical instances to a set of manageable conclusions" (p. 145).

The present study aims to understand how gamification and its mechanics have been researched and implemented in the T\&H industry, focusing on relevant service literature on gamification. The study pursues multiple purposes: first, to determine the key themes and concepts put forward in scientific papers; second, for each theme, to identify the main categories of affordances, outcomes and benefits; third, to analyze the results presented in the papers; and finally, to summarize relevant research gaps to generate future opportunities for service research and practice.

To synthesize the existing evidence on gamification usage in the T\&H sector and to support the development of evidence-based guidelines for academics and practitioners (Kitchenham et al., 2008), the present study employs a SLR, adopting a systematic quantitative approach (Pickering and Byrne, 2014; Pickering et al., 2015). This approach integrates qualitative and quantitative evaluation and provides a reproducible process of selection, analysis and reporting of the summarization of reviewed studies (Denyer and Tranfield, 2009).

A systematic and quantitative approach is crucial to map the boundaries of what is known and thus shed light on what is yet to be known (Pickering et al., 2015). The approach of study is systematic as the methods used to survey and select the papers are reproducible (Pickering and Byrne, 2013). Systematic quantitative reviews have been previously applied in the T\&H context (Weiler et al., 2012; Yang et al., 2017; Ruhanen et al., 2015), but without a focus on the significant phenomenon of gamification.

\subsection{Systematic review procedure}

We utilized the protocol for the systematic quantitative review process, proposed for social sciences by Pickering and Byrne (2014) and Pickering et al. (2015). It consists of five steps: (1) determining review aims and formulating research questions; (2) identifying search terms, databases, and literature selection criteria; (3) searching the databases for the literature and screening search outcomes against the criteria before refining the criteria; (4) appraising literature quality and relevance, structuring summary tables through the relevant information of existing eligible literature; (5) synthesizing and reporting findings and research gaps.

3.2.1 The SLR's aims and research questions. In line with the approach adopted by Følstad and Kvale (2018), specific research questions contextualized in the T\&H industry were stated to guide the SLR:

(1) What are the key themes recurring in the reviewed research?

(2) What are the most frequent affordances, outcomes and benefits deriving from the use of gamification for each theme?

(3) What are the results and critical issues for the detected themes in T\&H sector and service research?

(4) What further research is proposed by previous studies?

By following the above questions, the study extracts, summarizes and analyzes the pivotal elements of the reviewed papers, allowing the identification of key themes of gamification research in the T\&H industry. 
JSTP 31,5

698
3.2.2 Search query, inclusion criteria and database. The search of the literature in the Scopus database was conducted using the following search query:

TITLE-ABS-KEY (gamif* AND touris* OR travel* OR accommodation OR hospitality OR "sharing economy" OR "peer-to-peer platform")

The search considered the terms gamif*, touris* and travel* to include all possible forms deriving from the root.

Following the guidelines of Pickering and Byrne (2014) and Moher et al. (2009), the following initial inclusion criteria regarding the characteristics of the publications were set:

(1) To include article, conference papers, book chapters and reviews,

(2) To consider research written in English,

(3) To cover articles published since 2011.

Regarding the typology of papers, it was decided to include articles and conference papers, as in previous literature reviews it emerged that the majority of gamification publications derive from conference proceedings and articles published in journals (Koivisto and Hamari, 2019; Seaborn and Fels, 2015). Moreover, book chapters and reviews were also included to perform a more complete and accurate analysis. The study considers research conducted since 2011 as there has been a growing interest in gamification since the second half of 2010 (Deterding et al., 2011) from both academics and practitioners (Hamari et al., 2014a). The literature search was conducted in the Scopus database between July and September 2019.

The Scopus database indexes contents of all other databases with potentially relevant content (e.g. ACM, IEEE, Springer, AIS Electronic Library and DBCP Computer Science Bibliography) (Warmelink et al., 2018) and, as recognized by Wang et al. (2019, p. 166), it provides access to "reliable, robust and cross-checked data" (Galvagno et al., 2014). Indeed, Scopus is widely used in academic research (Macke and Genari, 2019). It functions as a search engine of other databases, producing the most results, its advanced search capabilities exceed those of other databases, and it is particularly focused on social science content (Yang et al., 2017). In addition, as pointed out by Parè $e t$ al. (2015), conducting the research on a unique database helps to ensure the clarity, rigor and replicability of the process, avoiding redundancy and overlapping. This is also confirmed by several studies (Hamari and Keronen, 2017; Majuri et al., 2018; Rajanen and Rajanen, 2019) which recognize that using one database instead of conducting searches in various repositories is preferred to increase the rigor and clarity of the data gathering.

3.2.3 Search outcomes, screening and refining criteria. The literature search resulted in a total of 156 records, collected in an Excel spreadsheet (Følstad and Kvale, 2018). For each record, the following data were collected: title, authors, authors' affiliation, abstract, keywords, publication year, source, type of work (article, conference paper, review or book chapter), research approach and research context. To detect the primary studies, namely the ones that have to be considered for analysis (Moher et al., 2009), further strict inclusion criteria were established. In particular, in line with the aim of the paper, the researchers focused on identifying studies that mainly deal with gamification applications in the T\&H industry. Furthermore, the studies grounded in the IT development of the gamification application were considered out of scope. This assessment was conducted in parallel by three researchers, during the analysis of titles, abstracts, and keywords of each record included in the spreadsheet (Følstad and Kvale, 2018). Subsequently, the three outputs were compared, and a filtered spreadsheet was defined. At the end of this phase, three duplicate studies were identified, 100 hits were excluded as inconsistent with the refined criteria, and 53 studies were 
selected for eligibility and therefore for full-text analysis. To facilitate efficiency and the Gamification in traceability of papers included/excluded at the different phases of the literature search, Figure 1 provides the PRISMA flowchart adapted from Moher et al. (2009).

3.2.4 Literature appraisal and summary. To evaluate the 53 studies, the full texts were thoroughly reviewed and analyzed and the Excel spreadsheet was integrated with additional information such as: Study approach (conceptual or empirical), Methodology (qualitative, quantitative, or mixed method), Method of data collection, Country, Aim, Findings and Conclusion.

A total of 22 articles were excluded: 12 studies had a technical/engineering scientific context and 10 studies were not consistent with the research aim. Afterwards, on the 31 detected records, a cross-reference analysis (Cooper, 1989) was carried out, and five new hits were added. Thus, the final body of literature consists of 36 papers. Considering the research

tourism and hospitality

699

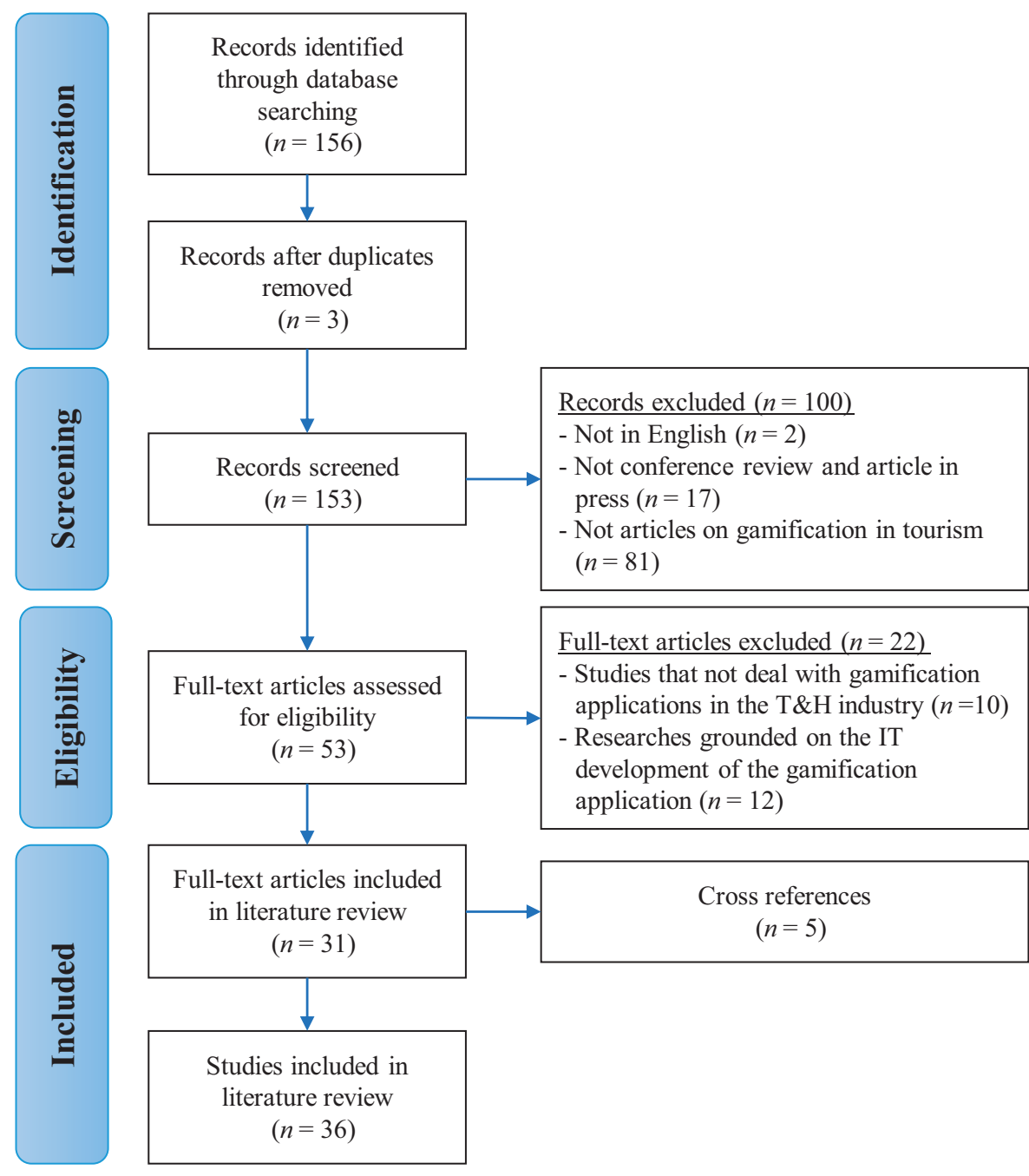

Figure 1.

Flowchart describing the literature search procedure 
JSTP 31,5

700

questions guiding the SLR, the 36 studies were deeply analyzed and coded to identify the main themes that characterize the use of gamification in the T\&H industry, together with the affordances, outcomes and benefits. These outcomes were managed and summarized by the development of multiple tables (Webster and Watson, 2002). In this phase the analysis was performed in parallel by two researchers and, to ensure the quality and rigor of the analysis, the other two researchers reviewed the whole process. In the event of discrepancy, the study was re-analyzed to resolve the conflicting view (Heinonen et al., 2018).

3.2.5 Summary of findings and research gaps. Starting with the data analysis and tables developed during the previous phase, the main findings of the SLR were synthesized. First, an introduction with a brief overview of bibliometrics characteristics and peculiarities of the analyzed works is provided. Second, a detailed explanation of the detected themes is presented, specifying aim, affordance, outcomes, gamification strategy findings and the benefits related to the adoption of gamification mechanics in T\&H. Third, a cross-analysis of the identified themes is presented, discussing the gamification pivotal elements: affordances, psychological and behavioral outcomes, and benefits (Deterding, 2015; Hamari et al., 2014b; Huotari and Hamari, 2017; Koivisto and Hamari, 2019). This gamification conceptualization is appropriate in analyzing a literature review for its level of abstraction, to enable identification of those pivotal elements in the reviewed records, allowing comprehension of how gamification is revealed (Hamari et al., 2014a). Finally, we highlighted the main critical issues affecting gamification application. On the basis of that, an agenda for future research on gamification is presented, considering opportunities for the $\mathrm{T} \& \mathrm{H}$ themes and service research.

\section{Review analysis and findings}

The selected papers were analyzed first author-centrically and then concept-centrically in order to extract the relevant information (Webster and Watson, 2002). The bibliographic details of 36 studies were synthesized in a summary table created using Microsoft Excel software. Although the gamification phenomenon spread in 2011 (Deterding et al., 2011; Hamari et al., 2014a), the literature search hits by year evidence the development of academic interest in gamification in the T\&H industry since 2015. In 2013, only one conceptual study (Xu et al., 2013) appeared. In contrast, 25 studies date back to the period 2017-2019, suggesting that interest in gamification in the T\&H context is rapidly increasing. As emerged from the authors' affiliation section in the summary table, most of the research on the gamification use in the T\&H comes from authors in China, the UK and Australia. Our study shows that 24 research papers were published in journals, five are book chapters, two are reviews and five studies were published in conference proceedings. As shown in Table 1, a

\begin{tabular}{|c|c|c|}
\hline Research approach & $\begin{array}{l}\text { Article } \\
\text { count }\end{array}$ & Study \\
\hline $\begin{array}{l}\text { Conceptual paper/ } \\
\text { literature review }\end{array}$ & 12 & $\begin{array}{l}\text { Sigala et al. (2019), Skinner et al. (2018), Swacha and Ittermann } \\
\text { (2017), Xu et al. (2013), Yung and Khoo-Lattimore (2019), Sigala } \\
\text { (2015c, 2018), Ramos et al. (2016), Wasan (2017), Gera and Hasdell } \\
\text { (2019), Kachniewska (2015), Shen and Joppe (2019) }\end{array}$ \\
\hline Empirical paper & 24 & \\
\hline Qualitative methodology & 7 & $\begin{array}{l}\text { Aebli (2019), Negruşa et al. (2015), Séraphin et al. (2017), Királová } \\
\text { (2015), Xu et al. (2016, 2017), Correa and Kitano (2015) }\end{array}$ \\
\hline $\begin{array}{l}\text { Quantitative } \\
\text { methodology }\end{array}$ & 8 & $\begin{array}{l}\text { Moro et al. (2019), Schuckert et al. (2016), Sigala (2015a, b), Yoo et al. } \\
\text { (2017), Mantouka et al. (2019), Yang et al. (2018), Tan (2018) }\end{array}$ \\
\hline Mixed methodology & 9 & $\begin{array}{l}\text { Fischöder et al. (2018), Séraphin (2019), Aguiar-Castillo et al. (2019), } \\
\text { Lee (2019), Liang et al. (2017), Garcia et al. (2019), Dingli and Mizzi } \\
\text { (2018), Mesáro et al. (2016), Tsai and Lee (2017) }\end{array}$ \\
\hline
\end{tabular}

Table 1.

Research approach 
total of 24 research papers are empirical studies, one is a literature review and 11 are conceptual papers. The empirical research most frequently adopts quantitative research methods. Specifically, our study reports that 17 studies employed a quantitative approach and seven reported qualitative analysis. The most frequent keywords utilized in the reviewed papers were: gamification (24), tourism (9) and motivation (6). From analysis of the domains of the studies, it emerges that most articles focus on online platforms, including Airbnb and Tripadvisor.

In order to extract, synthesize and analyze the results of studies, we used content analysis to classify the reviewed papers. In particular, the title, abstract, author's keywords, context, aim and research gap of the 36 papers were reviewed and coded. We extracted, summarized and analyzed the results of the studies to identify the main findings and further research for any field in the T\&H industry. In this way, we were able to identify five themes describing gamification research in T\&H (Figure 2): Edutainment, Sustainable behavior, Engagement factors, Service provider-generated content, User-generated reviews.

In the following sub-paragraphs, we explain the contents of the identified themes. First the meaning of the theme is presented. Then for every theme, the following key aspects were investigated: an overview of the gamification research aims; the affordances used to achieve the gamification scope; the linked psychological and behavioral outcomes; the gamification strategy results; and finally, the benefits detected in the reviewed papers following the classification provided by Huotari and Hamari (2017) (hedonic, utilitarian and social). To summarize the main elements detected through the SLR, ad hoc tables have been built (see Tables 2-6).

\subsection{Edutainment theme}

The Edutainment theme is a hybrid form combining the need to educate tourists and to provide entertainment through the use of IT systems (Hannigan, 1998). Poria et al. (2003) highlight the need to include personalized and engaged experiences in the tourism sector. The theme of tourism edutainment encompasses the different game mechanics which emerge from the reviewed papers, used for the purpose of educating or providing information and knowledge of tourist destinations, promoting local tourism and at the same time increasing tourists' involvement and entertainment (Hertzman et al., 2008; Markouzis and Fessakis, 2015).

The papers coded in this theme are summarized in Table 2 and highlight how game mechanics influence knowledge about cultural heritage attractions and promote the exploration of cultural heritage. Specifically, eleven studies analyzed the role of gamification as an educational tool: three were conceptual, and eight empirical. Most empirical studies carried out experiments (Lee, 2019; Séraphin, 2019; Fischöder et al., 2018; Dingli and Mizzi, 2018; Mesáro et al., 2016; Tsai and Lee, 2017) testing gamified mobile applications which provide information about cultural heritage, engage users and enhance the tourist-attractionvisiting process.
Gamification in tourism and hospitality 


\section{JSTP \\ 31,5}

702

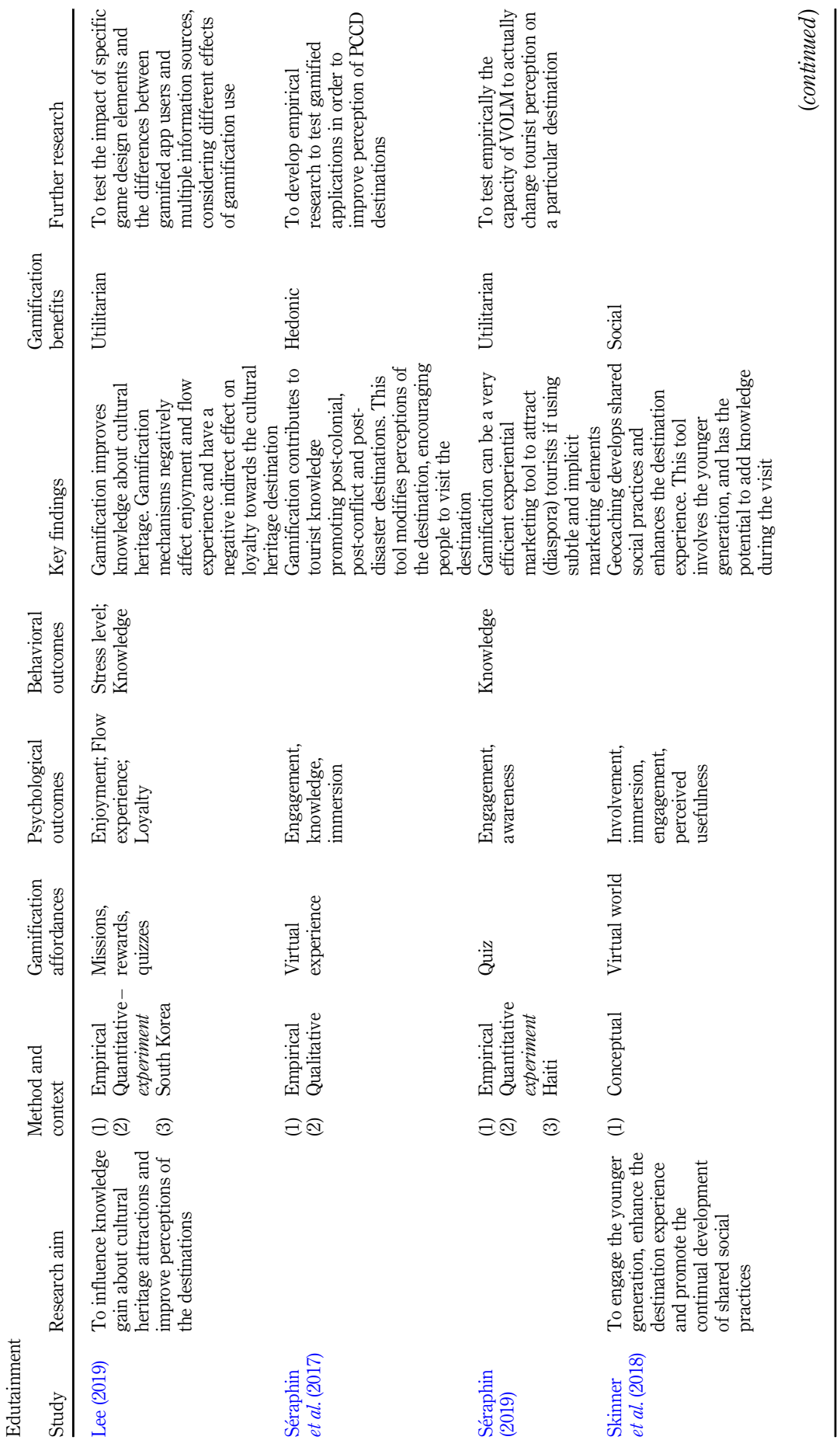

Table 2.

Edutainment theme

啲 


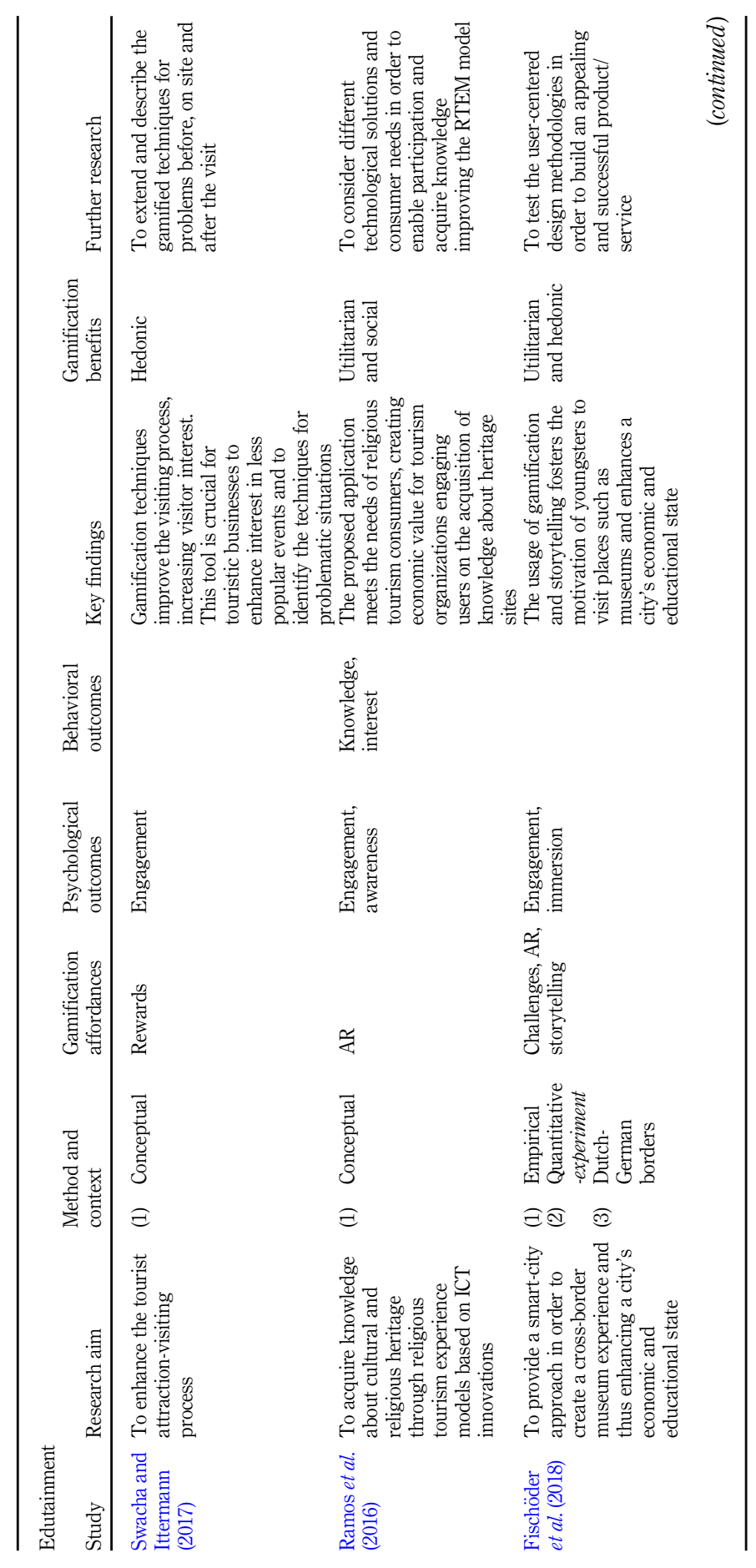

Gamification in tourism and hospitality

703

Table 2. 


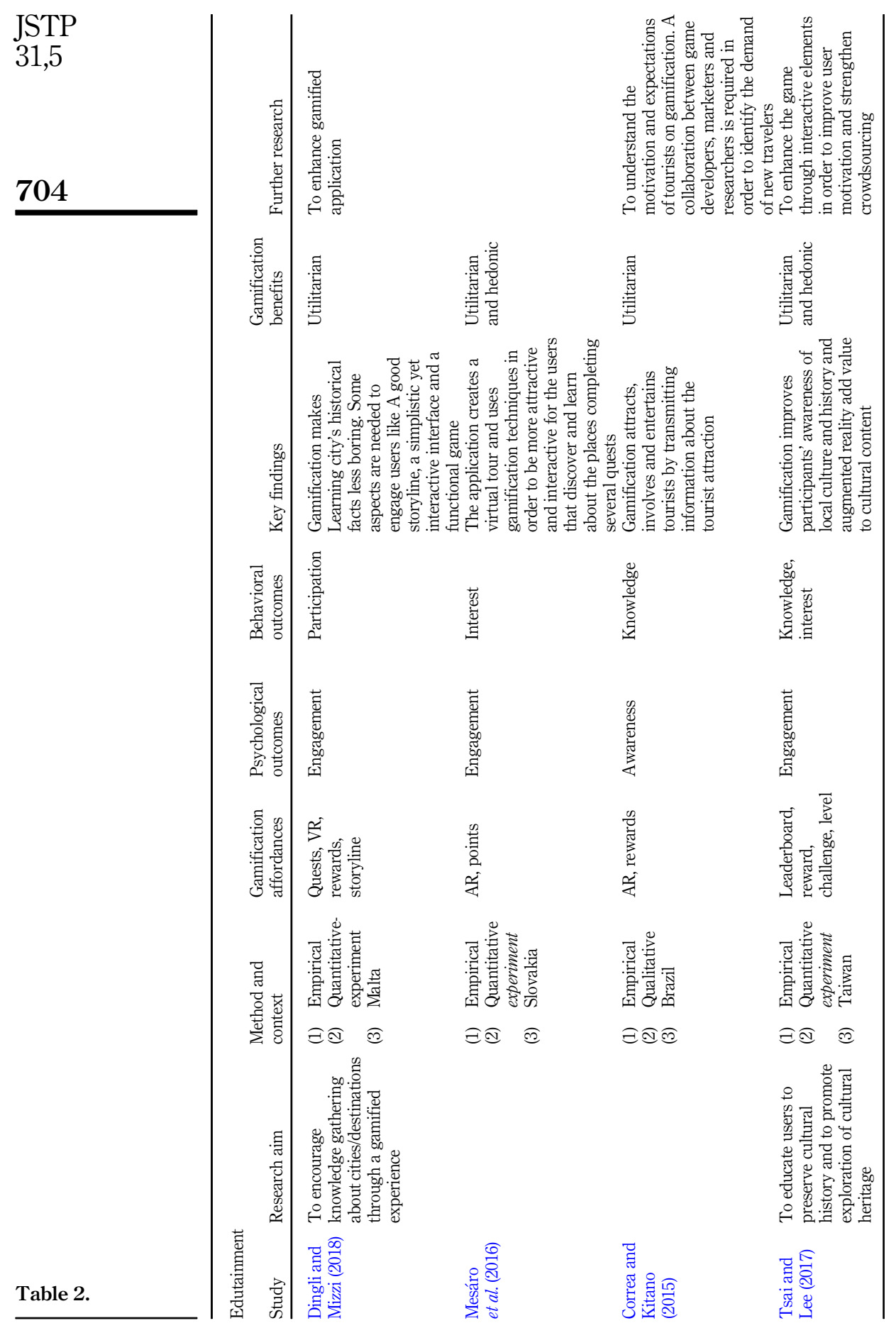




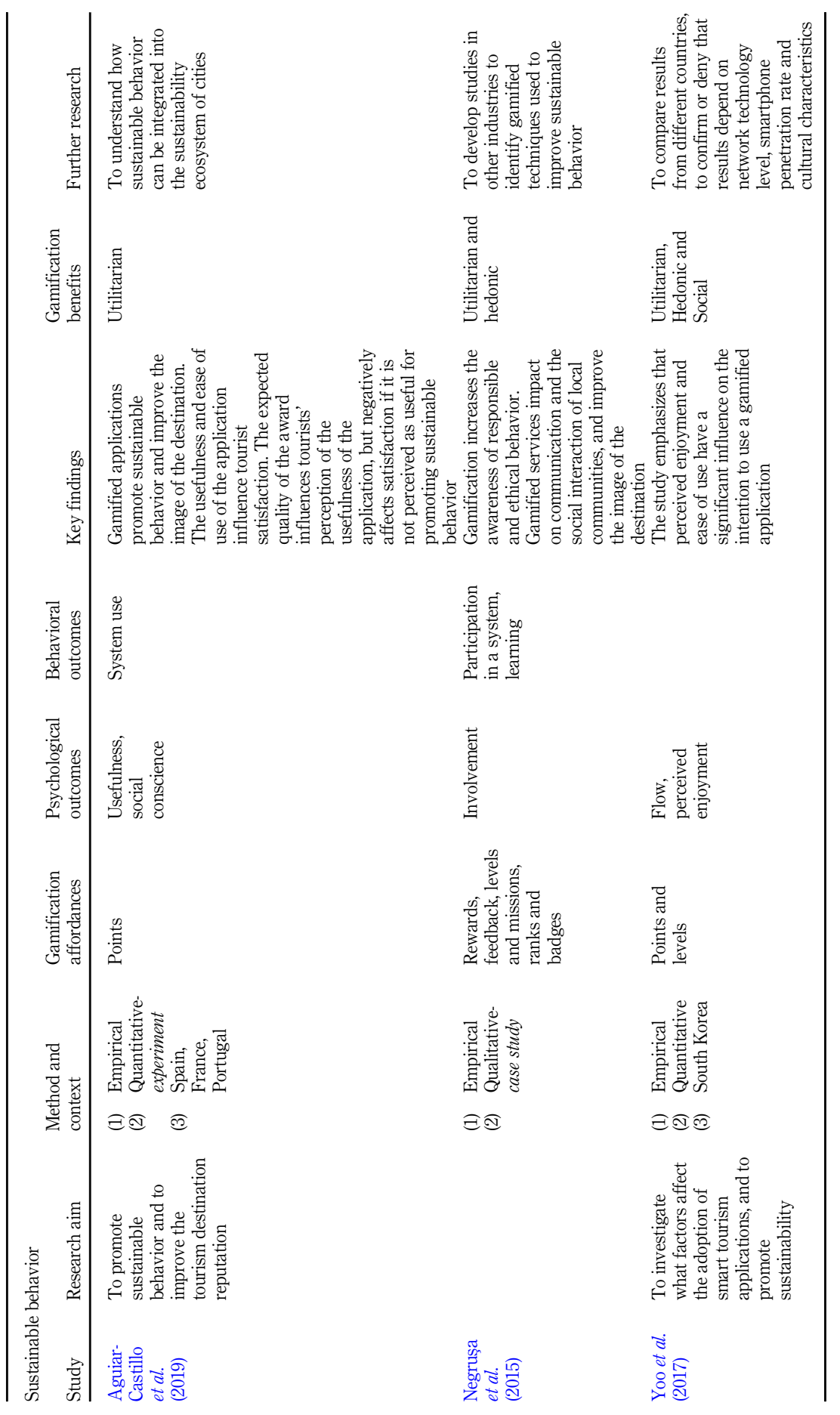

Gamification in tourism and hospitality

705

Table 3.

Sustainable behavior theme 


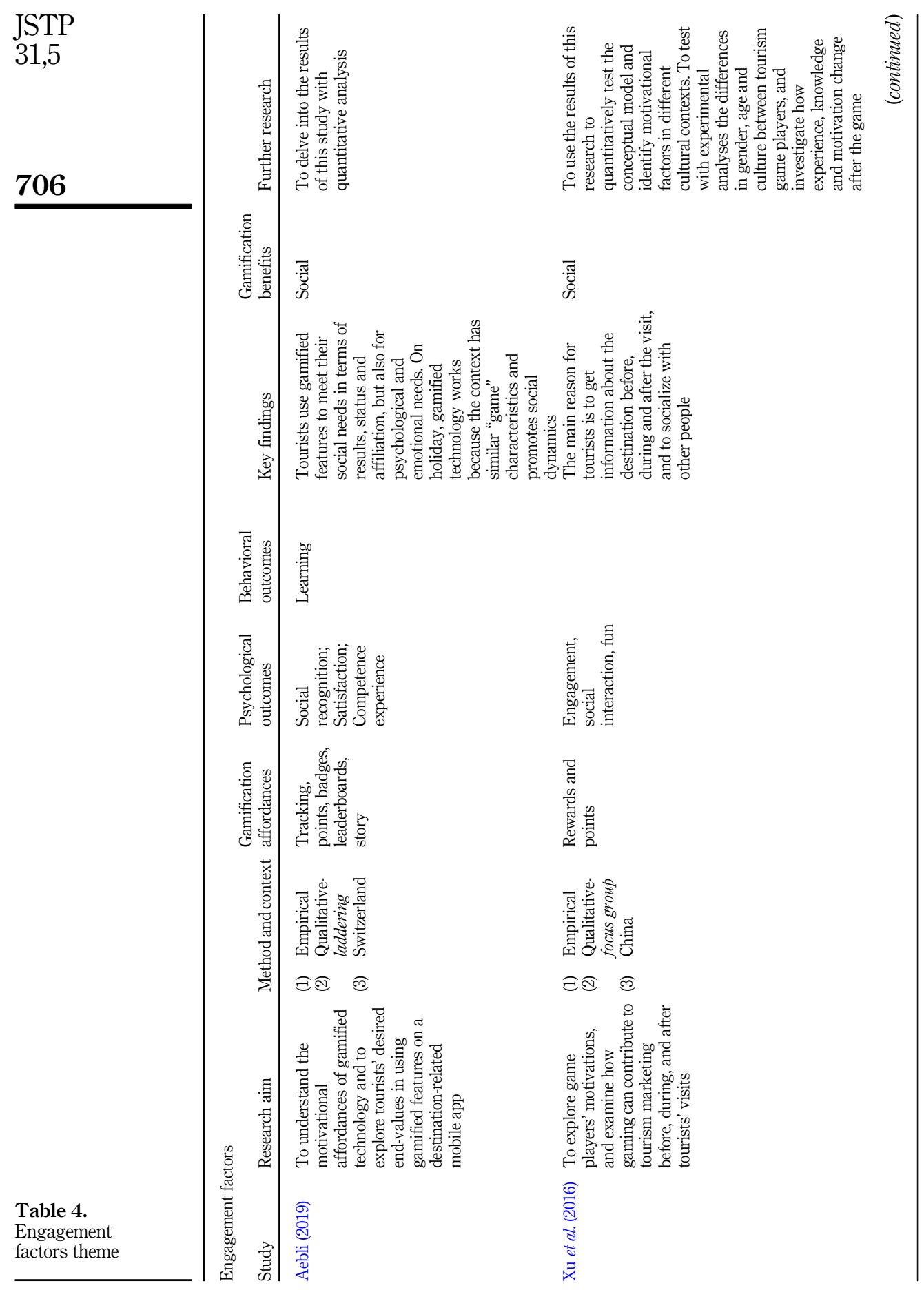




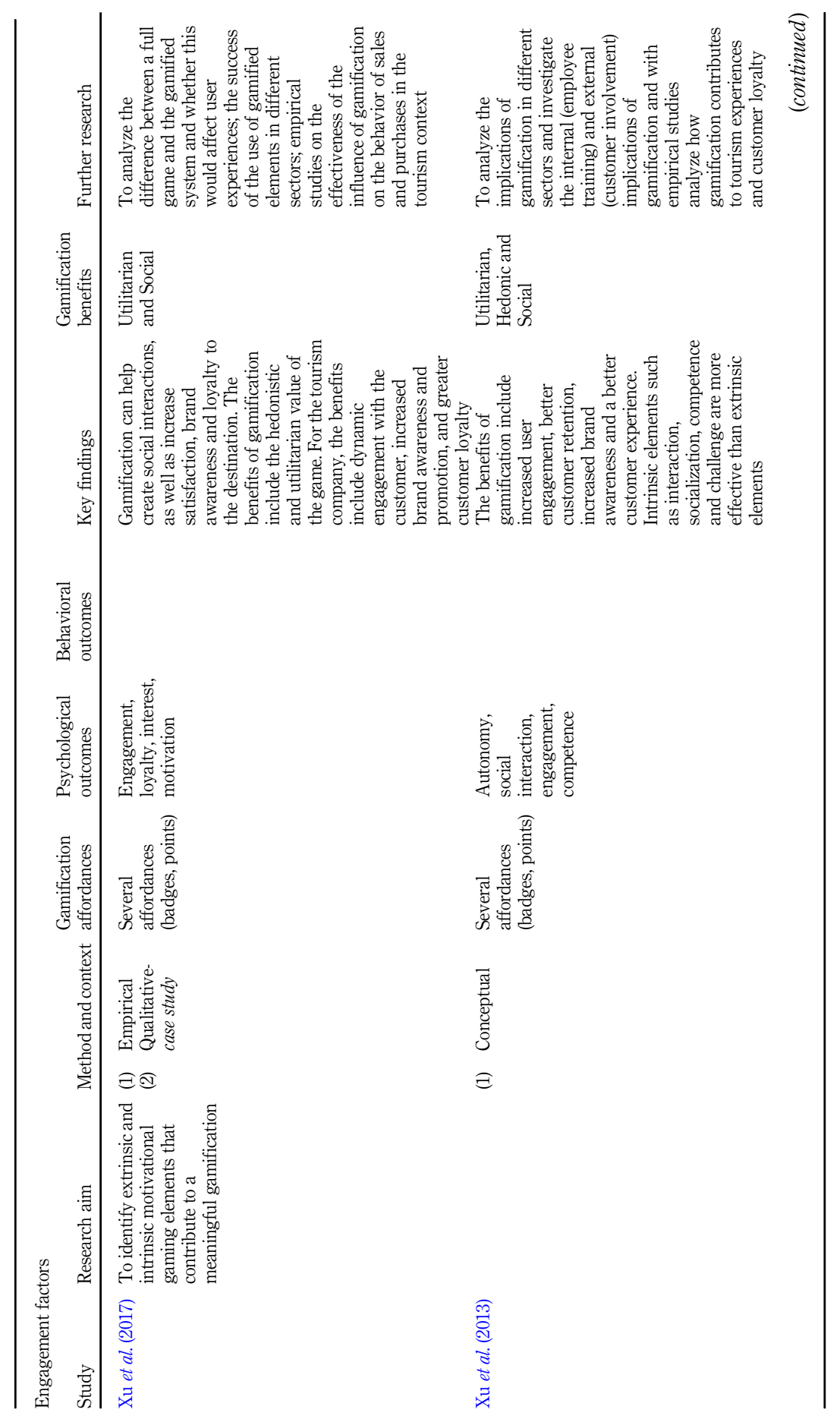

Gamification in tourism and hospitality 


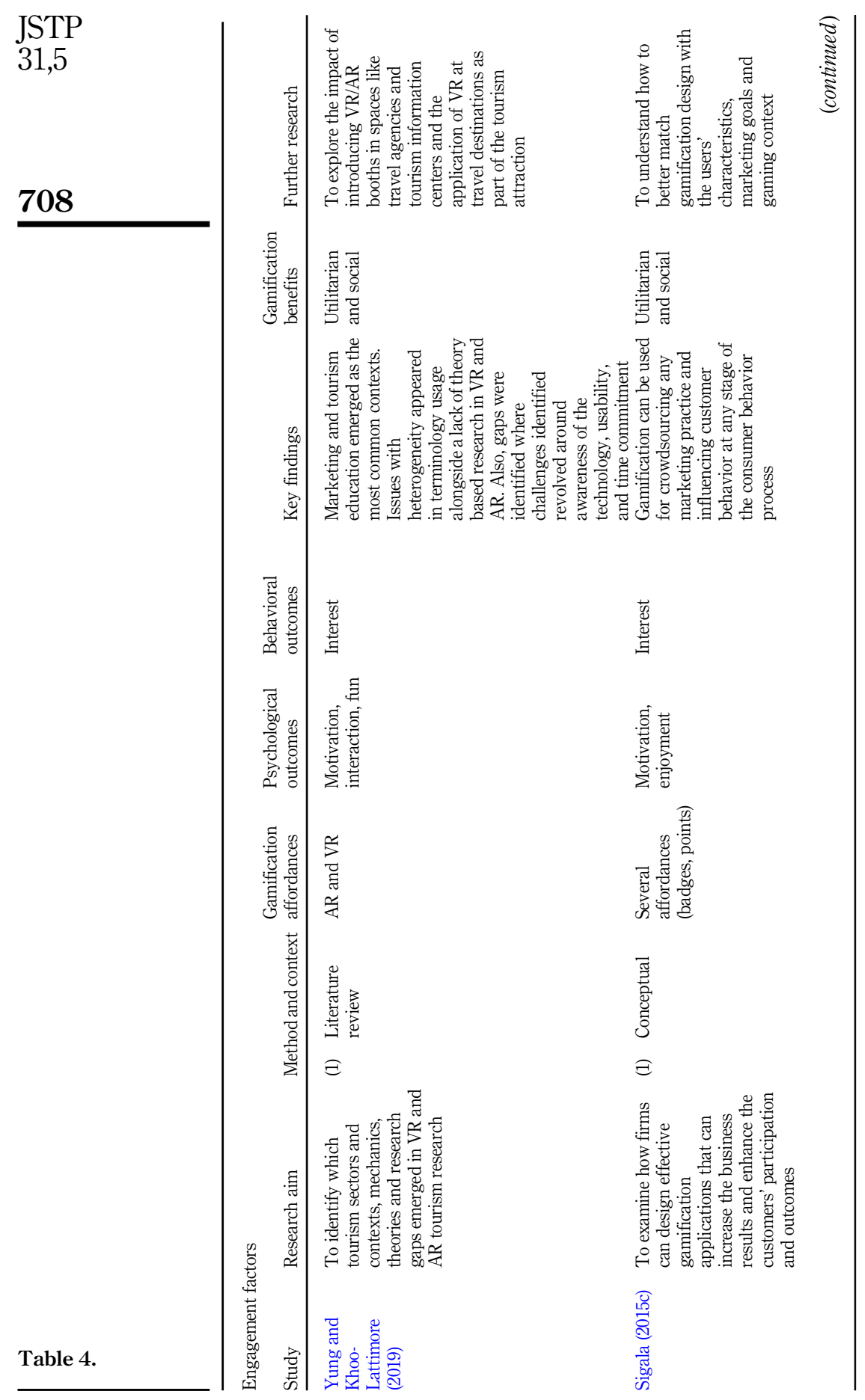




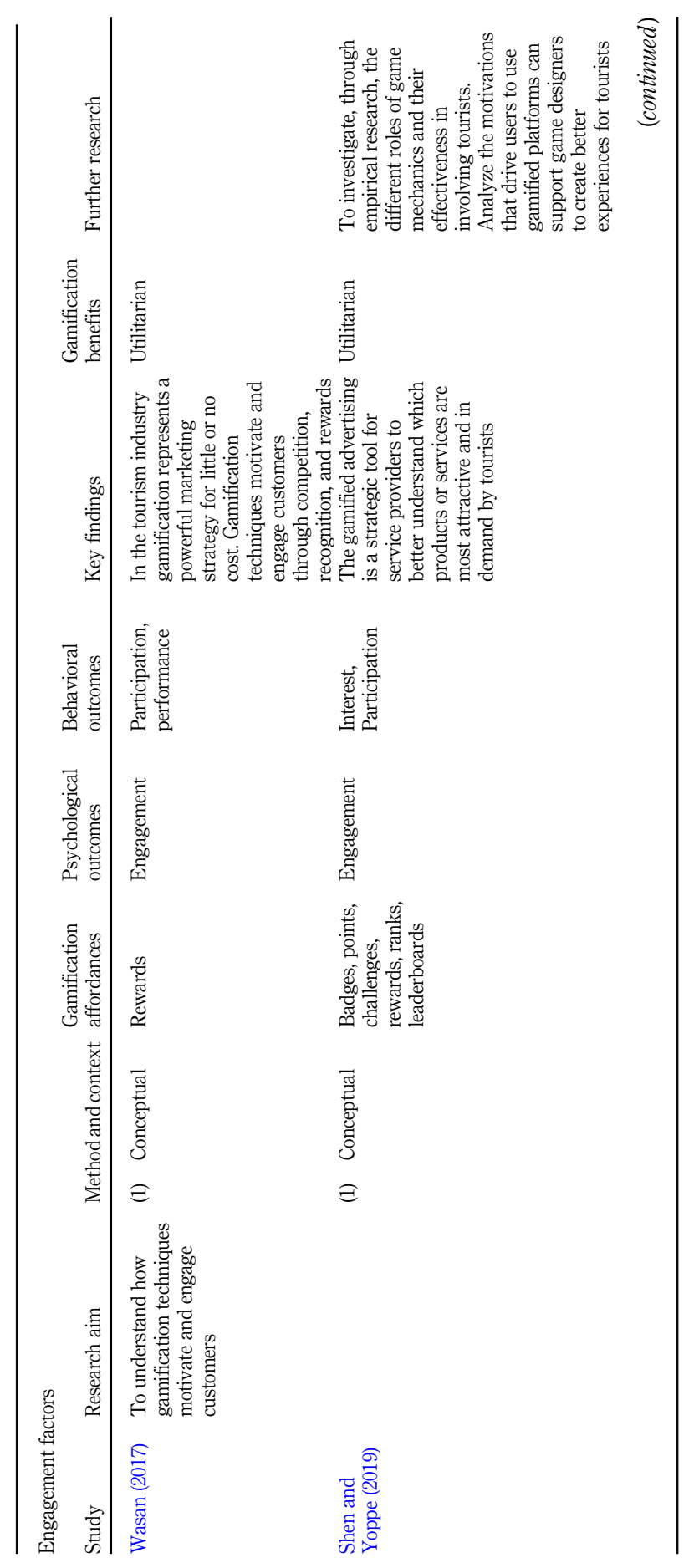

Gamification in tourism and hospitality

709

Table 4. 


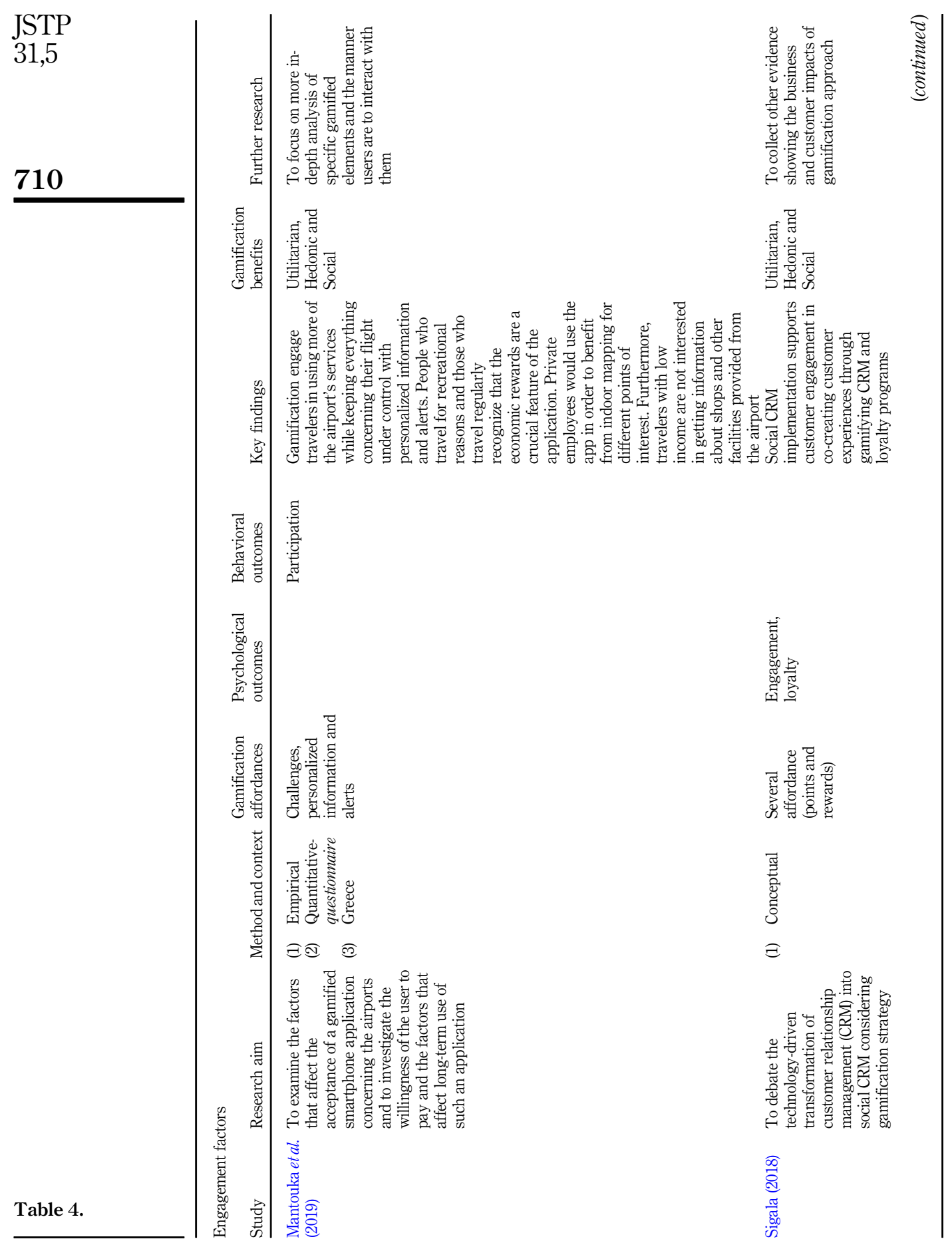




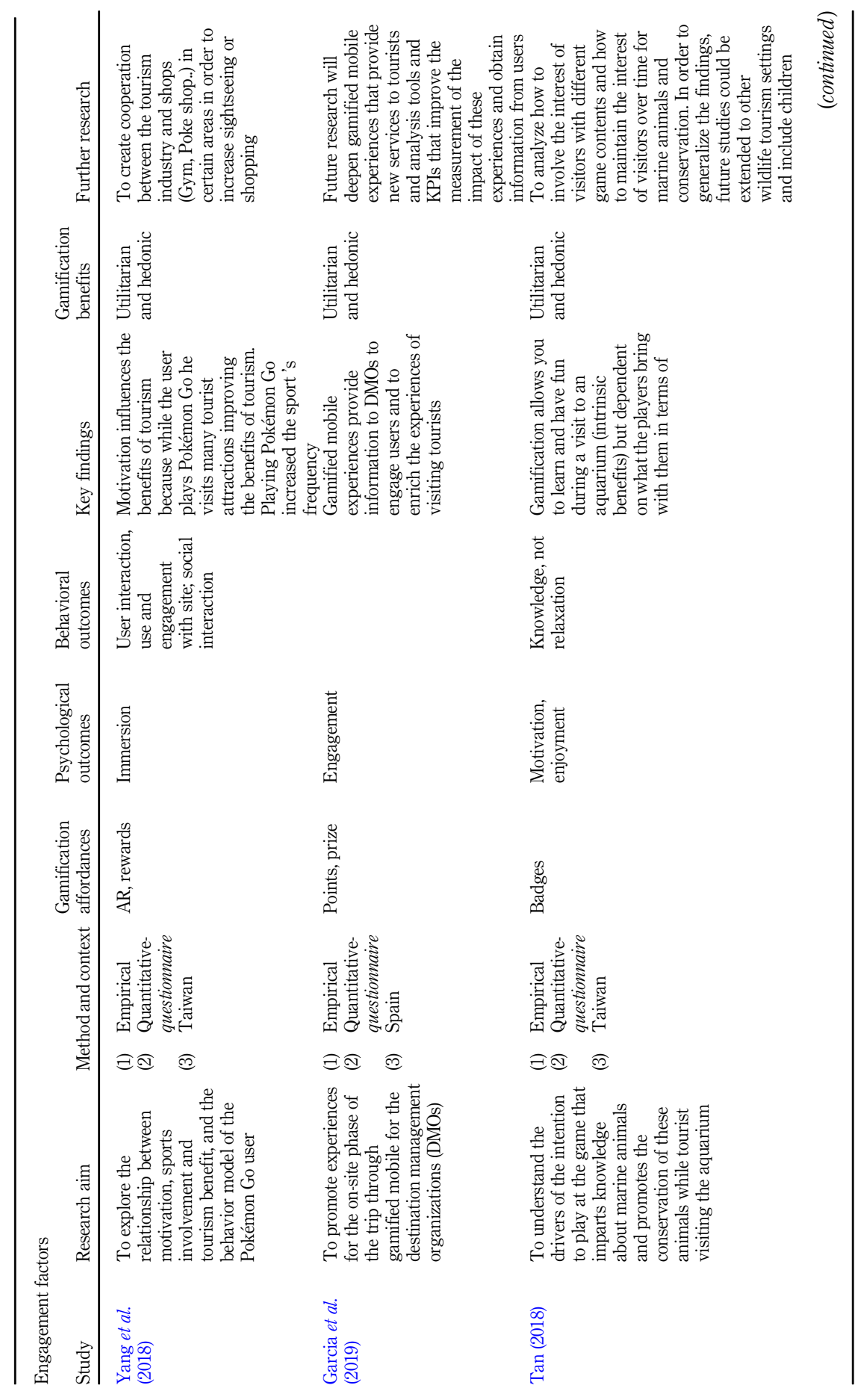

Gamification in tourism and hospitality

711

Table 4. 
JSTP
31,5

712

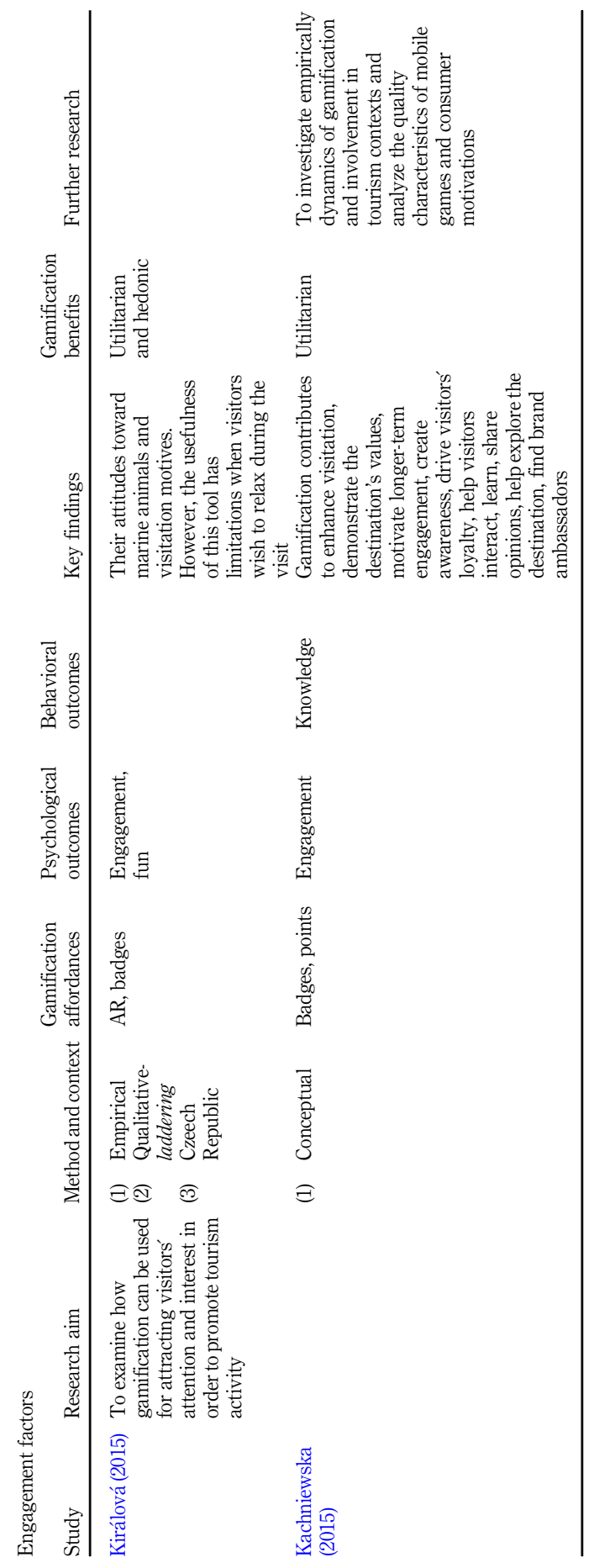

Table 4. 


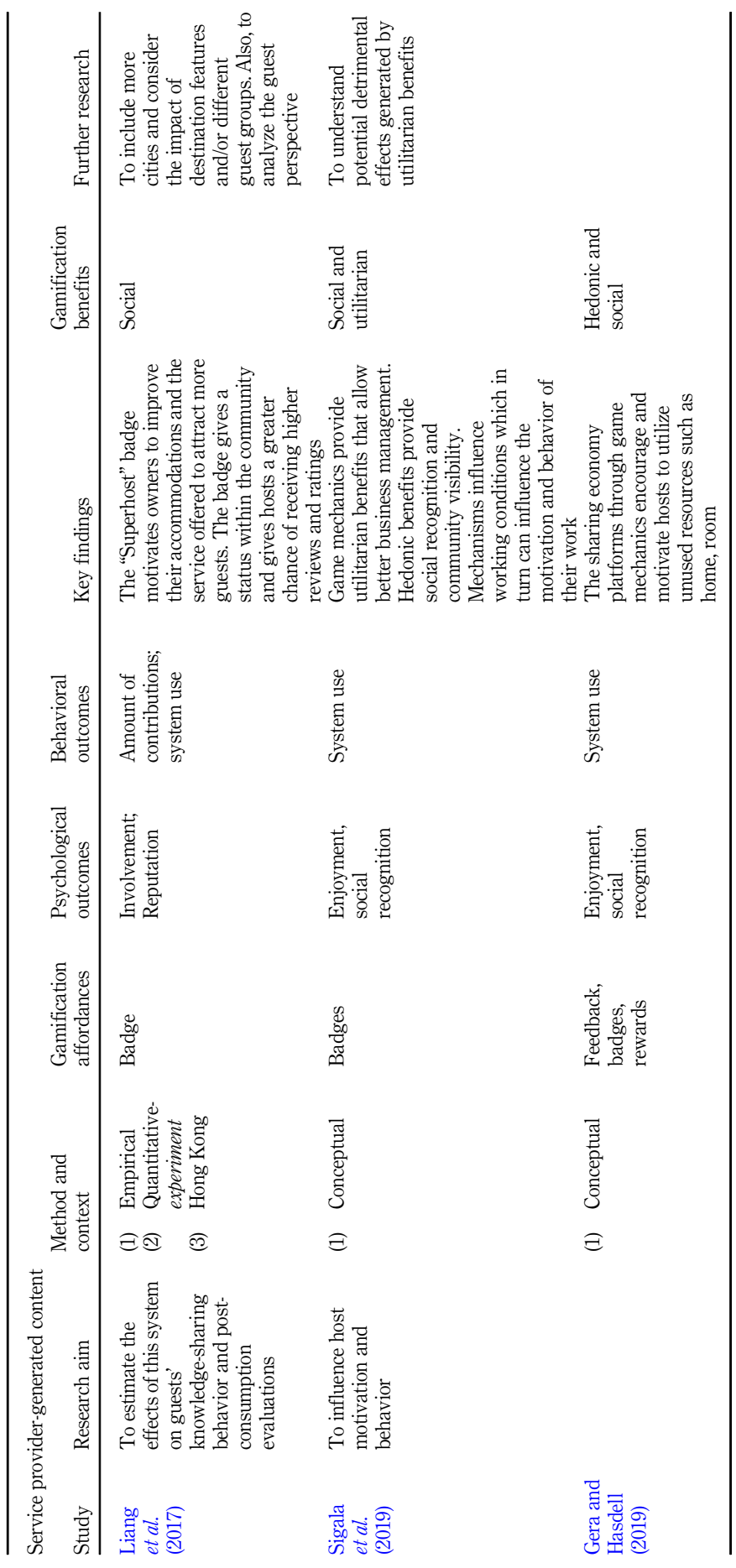

Gamification in tourism and hospitality

713

Table 5. Service providergenerated content theme 
JSTP
31,5

714

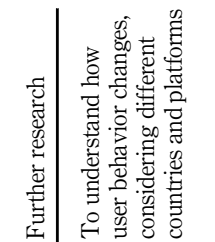

空
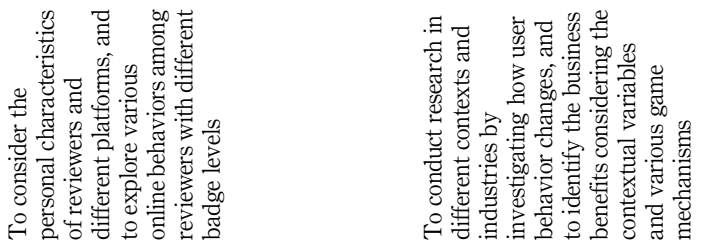

.

莺

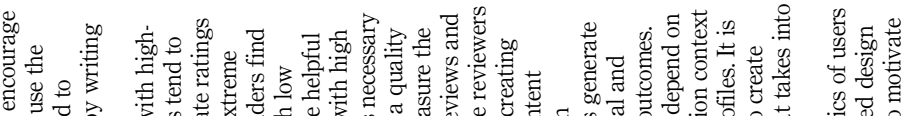

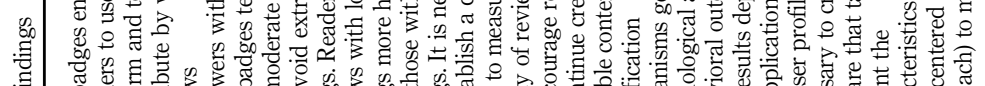

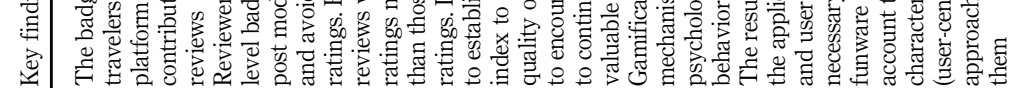

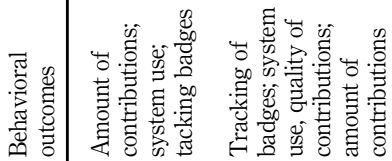

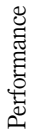

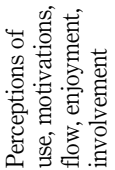

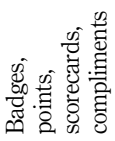

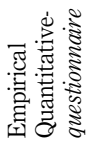

อิำ

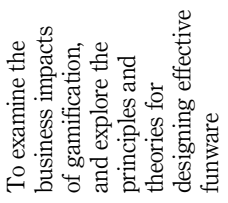

Table 6.

User-generated reviews theme

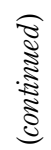




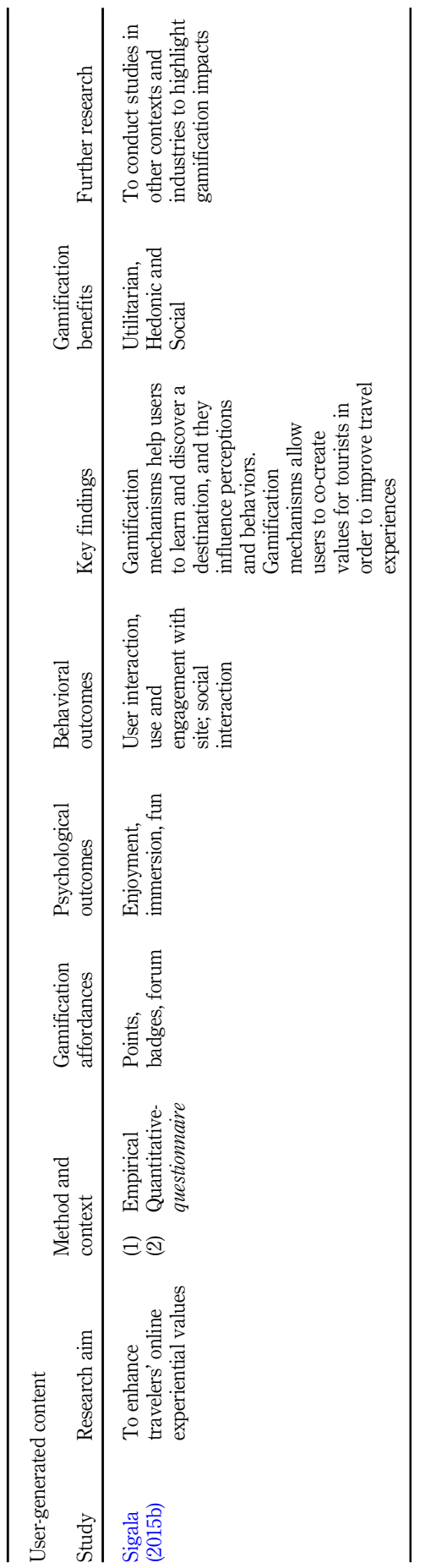

Gamification in tourism and hospitality

715

Table 6. 
JSTP 31,5

716
Concerning the affordances adopted, it emerges that the most utilized were virtual experience (Séraphin et al., 2017; Skinner et al., 2018; Ramos et al., 2016; Fischöder et al., 2018; Dingli and Mizzi, 2018; Mesáro et al., 2016; Correa and Kitano, 2015), rewards (Lee, 2019; Swacha and Ittermann, 2017; Dingli and Mizzi, 2018; Tsai and Lee, 2017; Correa and Kitano, 2015) and storytelling (Fischöder et al., 2018; Dingli and Mizzi, 2018).

In terms of psychological outcomes, these game mechanics generated engagement, immersion, increased awareness of the importance of cultural heritage and transferred knowledge/information, subsequently creating greater participation and interest in the tourist site (behavioral outcomes). Indeed, gamification may generate other behavioral outcomes, including positive stress associated with emotions such as joy, contentment and excitement and negative stress caused by unfamiliar quizzes/missions that users considered too challenging (Lee, 2019).

Research in the Edutainment theme demonstrates that gamified tools have a relevant role for educating about cultural heritage too, improving perceptions of the destinations and increasing the engagement of tourists, enhancing the experience before, during and after the visit (Swacha and Ittermann, 2017). Pre-visit tools can also encourage people to visit critical destinations (e.g. post-conflict or post-disaster destinations), promoting the acquisition of knowledge (Séraphin et al., 2017). On the site, gamification generates entertainment and engagement, and increases tourist satisfaction. After the visit, this game mechanic encourages the memory and sharing of the experience and encourages further visits (Swacha and Ittermann, 2017). Through gamification, tourism organizations engage users with the acquisition of knowledge about heritage sites (Ramos et al., 2016; Séraphin, 2019; Tsai and Lee, 2017; Correa and Kitano, 2015). In addition, the gamified systems guide tourists on where to find information on tourist destinations (Correa and Kitano, 2015). Tsai and Lee (2017) highlight how a game increases user participation, improves tourists' cultural identity awareness, and promotes local tourism. Scholars emphasize that gamified tools are crucial for the tourism business in encouraging millennials and Generation $Z$ to visit places such as museums, and sometimes enhance a city's economic and educational state (Fischöder et al., 2018; Skinner et al., 2018). Through gamification, learning the city's historical facts and locations of interest can be an enjoyable and productive experience (Dingli and Mizzi, 2018). The gamified application creates a virtual tour that is more attractive and interactive for users (Mesáro et al., 2016) and generates benefits for local economies, increasing tourism and realizing sustainable management (Tsai and Lee, 2017). However, research conducted by Lee (2019) reveals that gamification mechanics can also negatively affect enjoyment and flow experience and have an indirect negative effect on loyalty towards cultural heritage destinations (Lee, 2019).

The findings illustrate how gamification usage generates utilitarian and hedonic benefits, as well as tourism knowledge for users, by providing destination information in an interactive, pleasurable and engaging way.

\subsection{Sustainable behavior theme}

In several contexts, such as the $\mathrm{T} \& \mathrm{H}$ sector, the need has emerged to raise awareness and educate consumers by encouraging Sustainable behavior (Mair and Laing, 2013; Verplanken and Wood, 2006). Environmental issues have encouraged people to adopt environmentally friendly behavior (Kalafatis and Pollard, 1999). Many hotels are starting to implement innovative actions to reduce their environmental impact (Dief and Font, 2010). This theme includes and analyzes events and initiatives that encourage sustainable behavior within the community. Sustainable behavior depends on one's personal values, social motivations and contextual factors that can influence motivation. ICT systems, including gamification mechanics, are recognized as tools that can promote sustainability (Ali and Frew, 2013; Seaborn and Fels, 2015), favoring a transition to a more sustainable lifestyle. 
As shown in Table 3, the three studies included in the Sustainable behavior theme analyze the impact of the use of gamification mechanics on promoting and incentivizing sustainable behaviors, through quantitative (Aguiar-Castillo et al., 2019; Yoo et al., 2017) and qualitative (Negruşa et al., 2015) empirical studies. From the analysis of the reviewed papers, it emerges that the most common affordances implemented to promote the adoption of sustainable behavior are points (Aguiar-Castillo et al., 2019; Yoo et al., 2017) and levels (Negruşa et al., 2015; Yoo et al., 2017). These mechanics generate usefulness, social conscience and involvement, as psychological outcomes, and a more active participation with the system as a behavioral outcome.

Additionally, this theme explores factors influencing the adoption of sustainable behavior. In the T\&H context, gamification is used to raise tourists' awareness of economic, social and environmental sustainability issues by promoting sustainable tourism practices. These game mechanics generate information that spurs tourists on to use resources efficiently and improve the tourism destination's reputation by creating social interaction with local communities (Aguiar-Castillo et al., 2019; Negruşa et al., 2015). Conversely, Budeanu (2007) argues that users may resist changing their behavior to promote sustainability, particularly during holidays (Negruşa et al., 2015).

However, through game mechanics, it is possible to achieve the objectives of economic, social, and environmental sustainability by sensitizing users. The perception of usefulness, ease of use, and enjoyment of the application are crucial in influencing tourists and guiding their behavior (Yoo et al., 2017). Gamification improves the efficient use of resources and promotes sustainable behavior such as waste sorting (Aguiar-Castillo et al., 2019). These mechanics strengthen economic sustainability by increasing customer loyalty and brand awareness and by creating interactions that involve users in charitable acts.

Studies belonging to the Sustainable behavior theme have highlighted a positive change in user behavior, demonstrating that gamification usage generates utilitarian and hedonic benefits. Game mechanics enhance the tourist attraction visiting process, provide tourists with information on how to recycle, educate them about these sustainable practices, and encourage them to spread these habits/behaviors in their community (Aguiar-Castillo et al., 2019; Negruşa et al., 2015).

\subsection{Engagement factors theme}

The theme of Engagement factors investigates the incentives and factors that motivate tourists to interact with gamified technology, and examines how these mechanics can contribute before, during, and after tourists' visits. Identifying the factors that influence tourists to use gamified applications is crucial for companies to improve the service offered, and to create dynamic interaction between users and companies (Xu et al, 2013, 2016, 2017).

Fifteen papers analyze the Engagement factors theme (Table 4): eight empirical studies, using questionnaires (Mantouka et al., 2019; Yang et al., 2018; Garcia et al., 2019; Tan, 2018), laddering (Aebli, 2019; Királová, 2015), focus groups (Xu et al., 2016) and case studies (Xu et al., 2017); one literature review (Yung and Khoo-Lattimore, 2019) and six conceptual research papers (Xu et al., 2013; Sigala, 2015a, 2018; Wasan, 2017; Kachniewska, 2015; Shen and Joppe, 2019).

The studies analyzing Engagement factors note that the main affordances utilized to motivate and engage users are points (Aebli, 2019; Xu et al., 2013, 2016, 2017; Sigala, 2015a, 2018; Garcia et al., 2019; Kachniewska, 2015; Shen and Joppe, 2019), badges (Xu et al., 2013, 2016, 2017; Sigala, 2015a; Tan, 2018; Királová, 2015; Kachniewska, 2015; Shen and Joppe, 2019) and rewards (Aebli, 2019; Xu et al., 2016; Wasan, 2017; Sigala, 2018; Yang et al., 2018; Shen and Joppe, 2019). Engagement, enjoyment, motivation and social recognition are the 
JSTP 31,5

718

main psychological outcomes generated by game mechanics, whereas interest and participation among users and on site are the most recurrent behavioral outcomes.

As highlighted by Wasan (2017), in the T\&H industry there has been an increase in customer engagement technologies such as gamification, which have enhanced brand awareness, improved the quality of services, and provided assistance to tourists at every stage of the travel journey. Through gamified advertising, the service providers understand which services/products are most attractive to and most requested by users (Shen and Joppe, 2019). Game mechanics are used in all travel phases, from the preparation for the trip to the post-visit, providing useful material to users, for instance, information on the services available at the airport and on the flight (Mantouka et al., 2019). This fosters loyalty to the service/brand, influencing customer behavior at any stage of the consumer behavior process (Sigala, 2015c). Several studies (Aebli, 2019; Xu et al., 2016) show that tourists use gamified apps for curiosity, utility (to get information about destinations), to socialize and to increase satisfaction, brand awareness and loyalty to the destination ( $\mathrm{Xu}$ et al., 2013, 2017). Augmented and virtual reality create a multidimensional experience, encouraging visitors to interact with the attractions by offering sensorial immersion (Xu et al., 2013; Yung and KhooLattimore, 2019). From Aebli's exploratory study (2019), four motivational models emerge for the use of gamified technology during a holiday: success and desire for self-esteem through competition; social recognition; social interaction and connection with others; and reminiscence about experiences.

The study conducted by Yoo et al. (2017) on the adoption of the application of gamified smart tourism shows that the desire for interaction prevails over utilitarian motivations such as the collection of useful information for a visit. Moreover, through gaming users seek to increase self-esteem and social recognition within the community (Aebli, 2019). Gamification revitalizes the $\mathrm{T} \& H$ industry by suggesting new destinations/events and involving different targets (Kachniewska, 2015). This tool enhances customer co-creation and supports the social transformation of customer relationship management and loyalty programs (Sigala, 2018). Gamified mobile experiences provide information to DMOs (destination management organizations) to engage users and to enrich experiences during the on-site phase of the trip. Gamified mobile experiences allow DMOs to influence the behavior and to create interaction between DMOs and tourists (Garcia et al., 2019; Tan, 2018). Through gamification it is possible to enhance visitation, demonstrate the destinations' values, motivate longer-term engagement, create awareness, drive visitors' loyalty, help visitors interact, learn, share opinions and support visitors in exploring the destination (Királová, 2015).

Research within the Engagement factors theme has highlighted a positive change in user behavior, demonstrating that gamification usage generates social, utilitarian and hedonic benefits.

Regarding social benefits, it transpires from the reviewed papers that social needs are crucial for engagement with gamified technology (Aebli, 2019). Gamification creates interaction and socialization (relatedness) and has the potential to make other tourist users socialize with different local realities (Xu et al., 2013, 2016). On cultural heritage sites, gamification generates utilitarian benefits as well as tourism information and knowledge for users and in addition provides rewards such as free tourism tickets and sales coupons (Xu et al., 2017; Sigala, 2015a; Tan, 2018). The usage of gamified mobile experiences allows tourism service providers to obtain relevant information about tourists (Garcia et al., 2019; Shen and Joppe, 2019). This tool is crucial to attract the attention and interest of visitors (Királová, 2015) and to improve tourists' awareness of local culture and history (Kachniewska, 2015). Moreover, gamification mechanics improve gamified application usage and enhance the tourist attraction visiting process, generating hedonic benefits (Sigala, 2018; Yang et al., 2018). 


\subsection{Service provider-generated content theme}

The studies conducted on Airbnb were analyzed, incorporating these in the Service providergenerated content theme. The aim was to understand how user behavior changes through gamification affordances (e.g. the "Superhost" badge). Several studies have highlighted the crucial aspect of marketer-generated content in consumer decisions (Alboqami et al., 2015; Kumar et al., 2016). On platforms like Airbnb, there is a shortage of user-generated content (UGC), and content generated by the service providers (e.g. hosts) is necessary. The platform allows hosts to publish information about their property and themselves and guests choose the accommodation accordingly (Liang et al., 2020). Gamification guides service providers on how to use the platform and improve both the service offered and the service providergenerated content.

The Service provider-generated content theme analyzes how gamification mechanics influences host motivation and behavior in platform usage. The theme is composed of three articles, two of which are conceptual, and an empirical study (Liang et al., 2017) that shows the results of an experiment in Hong Kong (Table 5). The reviewed papers show that the most common affordances are the badges (Liang et al., 2017; Sigala et al., 2019; Gera and Hasdell, 2019). These generate psychological outcomes: enjoyment and social recognition, through the behavioral outcome of more frequent use of the Airbnb platform.

The findings of the studies note that Airbnb utilizes game elements to attract users to provide reviews. In particular, the platform offers game mechanics for the hosts, and through the "Superhost" badge, it incentivizes and guides them to improve the services offered. Accommodation providers (hosts) are driven by intrinsic motivations such as selflessness, competence satisfaction, self-development and social interaction, and thus Airbnb uses badges and travel coupons to engage hosts (Gera and Hasdell, 2019). Hosts must follow specific rules and challenges to obtain the "Superhost" status. This virtual status has the objective of frequently involving the hosts with the Airbnb platform by updating their listings and improving their services (Hamari et al., 2014a; Liang et al., 2017). Indeed, the badge provides intrinsic motivation for enhancing the quality of services, as well as obtaining more bookings and positive reviews. Studies have shown that guests are willing to spend more on apartments with "Superhost" badges.

On the Airbnb platform, the "Superhost" badge mechanic provides utilitarian benefits (such as priority support, supermarket discounts, webinars) and hedonic benefits (travel coupons or invitations to events). In addition, social recognition and visibility in the community allows hosts to receive more bookings and reviews (Liang et al., 2017; Sigala et al., 2019; Gera and Hasdell, 2019).

\subsection{User-generated reviews theme}

In the User-generated reviews theme, studies conducted on Tripadvisor are included. The studies analyze the gamification mechanics used by the website for increasing user reviews. Tripadvisor allows tourists to leave reviews on places visited, gaining badges and accumulating points according to their contribution in the community. Several studies observe that online user-generated reviews influence the number of online bookings (Ye $\mathrm{et}$ al., 2009), along with intentions to book and perceptions of trust (Sparks and Browning, 2011). Gamification encourages user involvement in and interaction with websites, increasing interest and engagement and improving the travel experience. Numerous studies emphasize the effectiveness of reviews generated by users in influencing the choices of other users (Cantallops and Salvi, 2014; Sparks and Browning, 2011; Ye et al., 2009).

As shown in Table 6, this theme explores how user behavior changes through gamification features and how game mechanics can enhance travelers' online experiential values. The User-generated reviews theme includes four empirical research studies that,

Gamification in tourism and hospitality 
JSTP 31,5

720

through questionnaires, analyze gamification effects on Tripadvisor (Moro et al., 2019; Schuckert et al., 2016; Sigala, 2015a, b). Badges (Moro et al., 2019; Schuckert et al., 2016; Sigala, 2015a, b) and points (Moro et al., 2019; Sigala, 2015a, b) involve and motivate users to generate reviews (psychological outcomes). Similarly, behavioral outcomes supported by the Usergenerated review theme examine the users' performance (number of contributions, tracking badges).

Research in the User-generated reviews theme demonstrates that the Tripadvisor platform adopts a gamified system to increase the interest and engagement of users by motivating them to contribute reviews. The research shows that gamification mechanics stimulate user involvement and interaction with the platform, encouraging user intervention to write reviews, thereby improving the travel experience and generating social and emotional benefits (Moro et al., 2019; Schuckert et al., 2016). Users find that the platform's gamified activities are a reliable and enjoyable way to evaluate the quality of travel information. The badge indicates competence, and users are active on the platform to obtain "status" in the community. The mechanics adopt a user-centric design and are based on intrinsic motivation that improves travel experiences and co-creates value for tourists (Sigala, 2015a, b).

The key findings highlight that the affordances implemented in Tripadvisor generate utilitarian and social benefits. Indeed, Tripadvisor utilizes game mechanics to incentivize users to interact with the website and write reviews, thus allowing players to acquire a reputation within the community (Moro et al., 2019; Sigala, 2015a, b), and also provide information to other users to improve travel experiences.

\section{Discussion}

The SLR findings indicate that gamification may represent a pivotal strategy for services, confirming its attractiveness for service scholars and practitioners (Mulcahy et al., 2020). This is particularly true in this time of fierce competition and intense crisis, when service providers need to identify innovative tools and strategies to stay on the market successfully and sustainably. The present study provides an analysis of how gamification research has developed so far and the effects it has generated in the T\&H field, confirming it as a sector with relevant potentialities for applying gamification (Buhalis et al., 2019; Sigala, 2015a; Schuckert et al., 2015). Indeed, gamification can be successfully adopted during all three phases that constitute the tourist journey as identified by Grönroos (2007): pre-visit, on-site and post-visit.

The SLR results present potential implications and relevant insights for service literature. In the findings section, five main themes of gamification research in T\&H have been detected and presented: edutainment, sustainable behavior, engagement factors, service providergenerated content and user-generated reviews. Although the themes were detected in a specific context, it is interesting to note their suitability for a wider interpretation in service research. The analysis reveals the valuable contribution of gamification strategies in transmitting knowledge and increasing awareness among users. Gamification has largely been adopted and studied in the education field (Huang et al., 2019; Van Roy and Zaman, 2018; Kim et al., 2018; Dicheva et al., 2015), besides being successfully adopted in other contexts with the purpose of educating users in terms of content and behaviors (i.e. Kapoor et al., 2020; Konig et al., 2019; Ryu et al., 2018; Morganti et al., 2017). Therefore, the SLR confirms gamification as a significant tool to raise awareness on sensitive topics, such as sustainability (Aguiar-Castillo et al., 2019; Mulcahy et al., 2018; Yoo et al., 2017; Negruşa et al., 2015), transformative service (Mulcahy et al., 2020) and wellbeing (Johnson et al., 2016). The findings emphasize that the greatest gamification appeal is to produce more significant involvement and engagement (Brigham, 2015). In agreement with Breidbach et al. (2014), the SLR underlines the remarkable contribution of gamification to the realization of an engagement 
ecosystem through gamified system mechanics, enhancing the overall users' experience (Kankanhalli et al., 2012). Indeed, gamification represents an innovative tool to promote consumer interaction and participation in the co-creation of experiences/services (Leclercq et al., 2018).

Furthermore, the analysis highlights that generating content is crucial for both users and service providers. This is in line with the wide diffusion of existing gamified applications grounded on user/service provider-generated content $(\mathrm{Xu}, 2011)$ in multiple contexts (health, mobility, productivity, sustainability, education). A gamified system guides the service providers' strategy to enhance service provision (Kumar et al., 2016). User-generated content reinforces the relationship with the company and improves customer trust and faith (Buckley et al., 2019), allowing people to benefit from the knowledge/experience shared by others in the form of comments and reviews (Macdonald and Brewster, 2019).

Next we present a cross-discussion of the identified themes, organized into two sections: first, the analysis of the pivotal elements constituting gamification: affordances, psychological and behavioral outcomes, and benefits (Koivisto and Hamari, 2019); second, the review of the main critical issues affecting gamification application in T\&H and service science.

\subsection{Affordances, outcomes and benefits in gamification research}

The SLR findings identify a set of motivational affordances (for instance, points, badges and rewards), demonstrating that these affordances generate psychological outcomes, such as involvement, engagement and social aspects. These results confirm what emerges from the literature on gamification (Helmefalk, 2019), corroborating its ability to create a relationship with the user (i.e. Hamari, 2017; AlMarshedi et al., 2017; Hamari and Koivisto, 2015) regardless of the motivation, or the sector in which the gamified system is implemented.

The main behavioral outcomes supported by gamification are the increase in the interaction with the platform system (for instance, in system usage, learning and knowledge), and the users' attention to monitoring their own personal performance (number of badges and points, number of contributions). This supports similar results highlighted in other sectors such as education (i.e. Majuri et al., 2018; Hamari, 2017); mobility (i.e. Olszewski and Turek, 2020; Marconi et al., 2018); crowdsourcing (i.e. Morschheuser et al., 2016); production and logistics operations (i.e. Warmerlink et al., 2020); and health (i.e. Johnson et al., 2016).

The SLR findings confirm that in order to engage users game mechanics need to afford extrinsic and/or intrinsic motivations: social, utilitarian and hedonic (Hamari et al., 2014b; Ryan and Deci, 2000a). Regarding social benefits, it transpires that social needs are pivotal for engagement with gamified technology (Aebli, 2019; Gera and Hasdell, 2019). Gamification creates interaction and socialization (relatedness) and has the potential to make users socialize with different local realities (Yoo et al., 2017; Xu et al., 2013, 2016). It is aligned with the main findings of service literature on gamification, namely that this technology facilitates social interaction within a service, and users can gain a sense of recognition by other users (Conaway and Garay, 2014). Gamification also allows for greater collaboration and engagement between stakeholders through user-generated content. The service is satisfying when it determines a sense of recognition from others, influencing users' attitudes towards utilizing the service. Concerning utilitarian benefits, the SLR emphasizes that game mechanics allow delivering education on recycling (Aguiar-Castillo et al., 2019; Negruşa et al., 2015), and providing information on cultural heritage sites (Lee, 2019; Xu et al., 2013, 2017; Yoo et al., 2017; Sigala, 2015a; Fischöder et al., 2018; Dingli and Mizzi, 2018; Tan, 2018; Mesáro et al., 2016; Kachniewska, 2015; Correa and Kitano, 2015). Moreover, gamified mobile experience usage allows service providers to obtain relevant information about tourists (Garcia et al., 2019). For instance, gamified advertising is a strategic and useful tool 
JSTP 31,5

enabling service providers to better understand which products or services are most attractive and in-demand by users (Shen and Joppe, 2019). The SLR recognizes the gamification role in fostering the efficiency of services and in triggering desired changes in users' behavior (Zichermann and Linder, 2010).

In addition, it emerges that gamification enhances the tourist attraction visiting process, generating hedonic benefits (Swacha and Ittermann, 2017; Yoo et al., 2017; Sigala, 2018) which include motivation and involvement in a gamified service. Many tourist destinations use gamified applications to convey destination information in an interactive, enjoyable and engaging way (Séraphin, 2019; Correa and Kitano, 2015). Thus, the SLR findings confirm that hedonic benefits make a service intrinsically motivating and enjoyable by promoting a positive attitude towards the system and prolonged use of the service (Van der Heijden, 2004).

Finally, the SLR reveals a strong connection between utilitarian, hedonic and social benefits, reinforcing the existence of the benefit-intertwined view postulated by Lin and Bhattacherjee (2008).

\subsection{Critical issues in gamification research}

The SLR analysis demonstrates that, through gamification, T\&H services generate value for both users and service providers. Users who co-create experiences are more involved, acquire information and knowledge and create social interactions. Simultaneously through these mechanisms, service providers can involve and train their employees, retain users, and from their feedback improve the quality of the services offered. Despite this, there appears a significant lack of balance in the perspective of analysis adopted in the reviewed papers. Most of the papers focus only on the users' point of view, analyzing engagement, perceptions, interactions, behaviors and benefits, while dynamics, effects and results from the service provider side seem neglected. The imbalance is particularly prominent in the empirical papers. This element represents a first critical issue of the existing literature for both the T\&H sector and services in general (Yung and Khoo-Lattimore, 2019; Sigala, 2018; Dorcic et al., 2019; Correa and Kitano, 2015).

Another under-investigated area highlighted by the SLR is the paucity of studies aiming to explore the negative aspects of gamification. The findings point to a lack of critical analysis of negative or undesired gamification effects. In the T\&H context, only two studies mention the limitations of gamification usefulness (Lee, 2019; Tan, 2018). This critical issue is detected also in the health context (Schmidt-Kraepelin et al., 2019; Johnson et al., 2016), in education (Toda et al., 2017) and in general services research (Thiebes et al., 2014). This has produced a significant increase in calls for research into potential gamification side effects, adverse events and mitigation practices (Koivisto and Hamari, 2019; Hyrynsalmi et al., 2017). For instance, specific aspects such as dependency (Attig and Franke, 2018), frustration caused by complex mechanics (Hamari and Koivisto, 2015), counterproductive effects (Diefenbach and Mussig, 2018) and unintended consequences (Rapp et al., 2018) have not been adequately investigated. It should not be assumed that adding games to serious contexts produces only positive outcomes (Rapp et al., 2016).

Finally, the third critical issue detected in the SLR findings is the frequent confusion between the terms "gamification" and "serious games." In some studies the term "gamification" is used when referring to applications/cases similar to serious games (Swacha and Itterman, 2017; Negruşa et al., 2015; Xu et al., 2013), whereas other studies conflate the two terms with no differentiation between them (Skinner et al., 2018; Xu et al., 2016, 2017). The line between "game" and "applications that simply incorporate elements of the game" can often be so blurred that it is not always clear which category is appropriate. Subjectivity and contextuality make it difficult to understand whether a system is a fullfledged game or a gamified system. In fact, it is often impossible to determine whether a given 
system is a real game or a gamified system, without taking into consideration both the intentions of the designers and, especially, the user experience (Deterding et al., 2011). The inconsistent use of terminology therefore requires greater academic clarity, in particular on how to differentiate gamified systems and full-fledged games (Larson, 2020). Furthermore, this critical issue has been experienced in other service fields such as education (Van Roy and Zaman, 2018) and health (Gentry et al., 2018).

\section{Agenda for future research}

Through the presented SLR, it has been possible to frame the current state of knowledge on gamification research in the T\&H sector, generating valuable future opportunities for service research and practice. Beginning with the research gap that characterizes $\mathrm{T} \& \mathrm{H}$ literature on gamification, we design a specific roadmap for identified themes (Figure 3). Moreover, through a comparison of the main critical issues arising from the SLR with existing service literature, we identify cross-context gamification aspects calling for further research.

First, for each theme detected in the T\&H sector, we propose specific directions for future research.

Regarding the Edutainment theme (Table 2), the need emerges for the development of further studies to identify gamified techniques that improve tourists' knowledge and sustainable behavior; to deepen the effectiveness of these behaviors by citizens; and to consider different gamification effects (both positive and negative). It is necessary to analyze the proposed techniques for enhancing the visiting process of tourist attractions, before, during and after the visit. It is crucial to understand the motivations and expectations of tourists on gamification. A collaboration between game developers, marketers, and researchers is required to identify the demands of new travelers. In the immediate future, new studies could contribute to understanding the role of gamification in the adoption of correct behavior after the pandemic.

For the theme Sustainable behavior (Table 3), future studies could be developed in various sectors and countries to identify gamified techniques that improve sustainable behavior, and to deepen knowledge of how gamification promotes ethical and correct practices (e.g. recycling behavior and limiting excess tourism in saturated destinations), by considering network technology level, smartphone penetration rate and cultural characteristics. In fact, in the upswing phase, the use of gamification could help to educate and change users' behavior by encouraging them to implement more correct and sustainable behavior.

Concerning the Engagement factors theme (Table 4), future research could test, in different cultural and social contexts, the models and factors that have emerged from the reviewed papers. Experimental analysis could test differences of gender, age and culture among tourism game players, and investigate how experience, knowledge and motivation change after the destination experience. Analysis of the incentives that drive users to use gamified platforms could support game designers in creating better experiences for tourists. Further research needs to explore whether culture, attitude to technology, and personality are mediators in influencing users through gamification mechanics. Future studies could investigate the internal (employee training), and external (customer involvement) implications of gamification, and analyze how gamification contributes to tourist experiences and loyalty.

In the Service provider-generated content theme (Table 5), it transpires that the impact of the destination characteristics and variations in groups of guests must be included in future studies. The SLR reveals the need to analyze the perspective of guests and hosts, highlighting the benefits and risks that gamification mechanics generate. The game mechanics implemented by Airbnb are aimed at hosts, and an interesting focus would be to

Gamification in tourism and hospitality 
JSTP
31,5

724

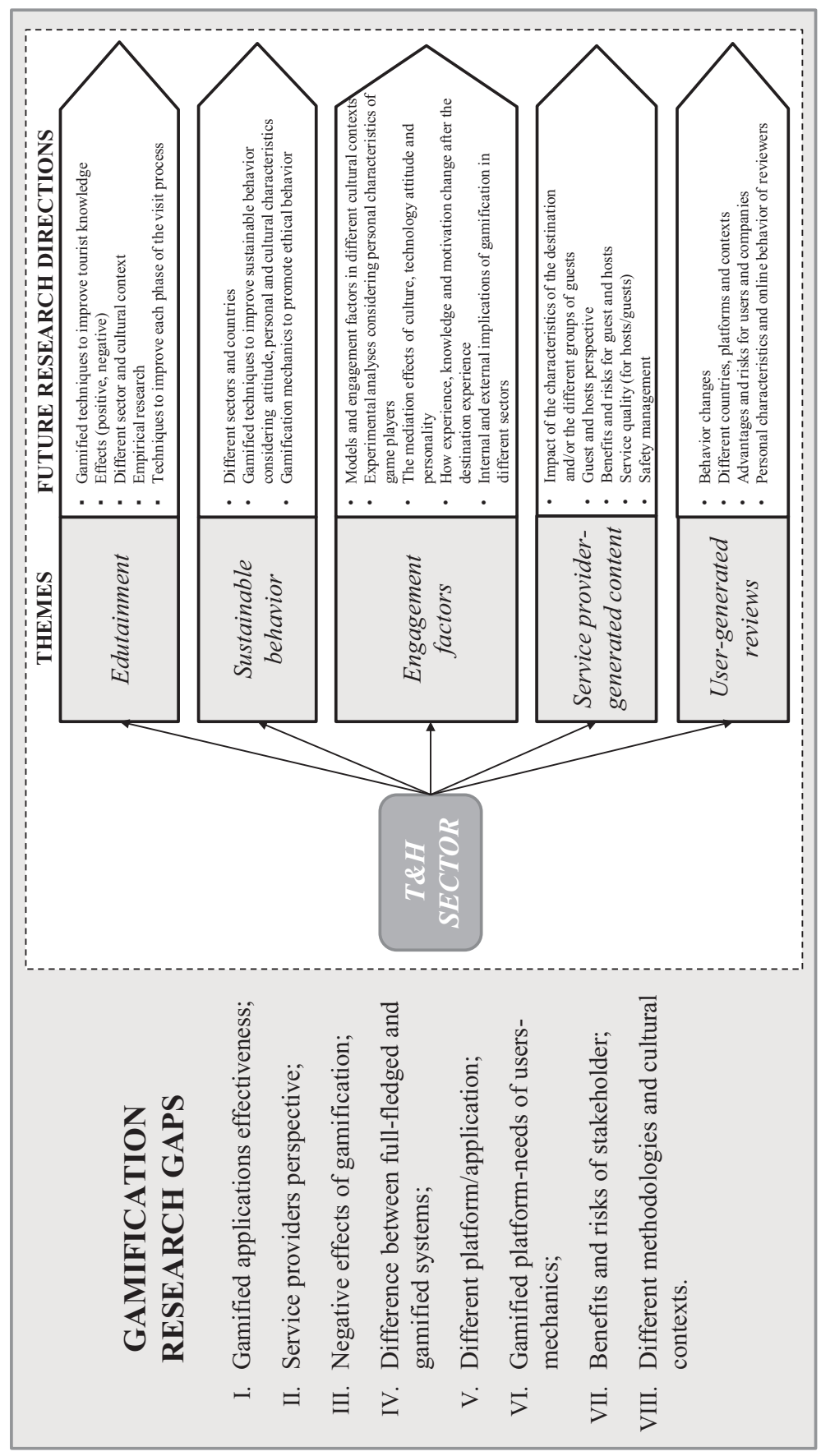

Figure 3.

Future research directions 
investigate how and if these mechanics improve service quality, and the consequent effect on guest satisfaction.

Finally, from the User-generated reviews theme (Table 6), there arises the necessity to understand how and why user behavior changes, considering different countries, platforms, and contexts, and to identify advantages and risks for users and companies. In particular, future research could consider the personal characteristics of reviewers and explore various online behaviors among reviewers with different levels of badges.

Second, comparing the SLR findings with existing knowledge, we propose general directions for gamification research in the service field. Indeed, the SLR suggests that gamification is able to support the co-creation of experiences by positively engaging both users and service providers through digital platforms and simultaneously pursuing different and customized purposes (Patricio et al., 2020; Hsu and Chen, 2018; Tsay et al., 2018). Nevertheless, the reviewed studies reveal the need to create digital platforms that use gamification with a user-centric strategy, considering different users' characteristics and preferences. In particular, these digital platforms use extrinsic elements such as points and badges, and intrinsic elements (competence, social recognition and so on) which must be holistically integrated with corporate objectives. Hence, future research should expand knowledge about the effectiveness of the contributions made by gamified applications.

In addition, the SLR confirms that very few contributions examine the service provider point of view (Dorcic et al., 2019). Future research must focus on the service providers' perspective and empirically analyze a company's aims, how and which motivational affordances are implemented, and the outcomes and benefits generated by the application of game mechanics. Service providers have to gradually develop their gamification system based on the company's objectives and capabilities and considering the users' needs (Chen, 2015; Negruşa et al., 2015). Similarly, our SRL highlights that it is crucial to understand and delve into the negative aspects of gamification which have been treated in relatively few research studies and contexts (Koivisto and Hamari, 2019; Hyrynsalmi et al., 2017).

The present research confirms the need for further studies aimed at clarifying the difference between full-fledged and gamified systems through empirical research in different domains (Larson, 2020; Klock et al., 2020; Lee, 2019; Patricio et al., 2018; Xu et al., 2017).

Furthermore, most of the reviewed empirical studies are not completely generalizable as many are focused on specific platforms and applications, or contextualized in a single country. This implies a need to test the findings of those studies in different cultural contexts, and with other platforms, to make their results more generalizable. Gamification strategy, to be effective, must understand all potential users and their needs in order to involve the players. Gamification impacts not only users, but rather all the sector's actors including tourists, service providers, digital platform providers and communities. In this regard, future research could map all the stakeholders involved, in order to identify the benefits and risks for each, and the most suitable gamification mechanics to involve them (Zainuddin et al., 2020; Klock et al., 2020; Xi and Hamari, 2020; Moro et al., 2019).

Moreover, it appears necessary to investigate the role of gamified platforms, considering the different needs of users. Specifically, there is a need for further investigation and analysis of the most effective mechanics, and the "right commitment" required from users to create a successful strategy for the service providers (Koivisto and Hamari, 2019; Garett and Young, 2019).

In particular, it emerges that further research should investigate, in multiple cultural contexts, how the intentions, behavior and satisfaction of users changes, and consider the potential negative effects that gamification can generate. These purposes could be achieved by implementing multiple methodologies (i.e. qualitative, quantitative, mixed methods and experiment) (Xi and Hamari, 2020; Zainuddin et al., 2020; Koivisto and Hamari, 2019).
Gamification in tourism and hospitality 
JSTP

31,5

726

\section{Conclusion}

The present study provides an overview of the existing literature on gamification use in the T\&H industry. The main contribution of the review is to identify key themes, highlighting the game mechanics, outcomes and benefits for each theme; discussing and synthesizing the main results; and providing a roadmap with future research opportunities for T\&H context, and service research in general. Our findings demonstrate that this field presents opportunities for development for both practitioners and scholars.

The spread of digital platforms has favored gamification implementation (Brigham, 2015), improving services and generating engagement and value for both providers and tourists/ users (Tobon et al., 2020; Breidbach and Brodie, 2017).

From the discussion there emerge practical insights to motivate companies and users to utilize gamification. Service providers, such as T\&H operators, could adopt strategies to satisfy intrinsic needs (e.g. social recognition), to attract, engage, and retain tourists and users (Sigala, 2015b), and to motivate their employees to achieve better business goals. For instance, on digital platforms such as Airbnb, following the gamification mechanics allows hosts to improve the services offered.

Our SLR shows the usefulness of gamification as it provides information and transfers knowledge to service providers and users. Indeed, through these game elements, users are more informed and involved, and they participate in the co-creation of value, while service providers acquire information from users. In addition, sustainable as well as healthy behavior can be promoted by educating and transmitting rules through games.

Notwithstanding its various contributions, this review study has some limitations. We have followed the guidelines of Parè et al. (2015) considering one database (Scopus) to ensure its quality, in terms of both rigor and relevance. The review procedure has been described in detail to ensure the clarity of the process, and to enable replication of the procedure. Despite several authors (Wang et al., 2019; Warmelink et al., 2018; Macke and Genari, 2019) suggesting that Scopus is the largest, complete online database of peer-reviewed literature and particularly relevant for social sciences research, some studies may have been missed by not including other databases.

Finally, further research is required to understand how innovative tools and strategies, including gamification, can be exploited to recover from the COVID-19 pandemic and to launch a new era in the tourism sector. Indeed, our research was conducted before this crisis which has drastically impacted international tourist mobility, causing a loss of $\$ 1.2$ trillion in export revenues from tourism and 120 million direct tourism jobs (UNWTO, 2020). This pandemic emergency may represent an opportunity for tourism companies to reformulate their strategy through technological innovation by evaluating the new needs of users (Sigala, 2020). Operating companies and organizations can use the findings of the present research to gain insight into new technology applications being implemented in the industry and find out how user engagement varies, considering several game mechanics.

\section{References}

Aebli, A. (2019), “Tourists' motives for gamified technology use”, Annals of Tourism Research, Vol. 78, p. 102753.

Aguiar-Castillo, L., Clavijo-Rodriguez, A., Saa-Perez, D. and Perez-Jimenez, R. (2019), "Gamification as an approach to promote tourist recycling behavior", Sustainability, Vol. 11 No. 8, p. 2201.

Alahäivälä, T. and Oinas-Kukkonen, H. (2016), "Understanding persuasion contexts in health gamification: a systematic analysis of gamified health behavior change support systems literature", International Journal of Medical Informatics, Vol. 96, pp. 62-70.

Alboqami, H., Al-Karaghouli, W., Baeshen, Y., Erkan, I., Evans, C. and Ghoneim, A. (2015), "Electronic word of mouth in social media: the common characteristics of retweeted and favourited 
marketer-generated content posted on Twitter", International Journal of Internet Marketing and Advertising, Vol. 9 No. 4, pp. 338-358.

Ali, A. and Frew, A.J. (2013), Information and Communication Technologies for Sustainable Tourism, Routledge, London.

AlMarshedi, A., Wanick, V., Wills, G.B. and Ranchhod, A. (2017), "Gamification and behavior", Gamification, Springer, Cham, pp. 19-29.

Anagnostopoulou, E., Bothos, E., Magoutas, B., Schrammel, J. and Mentzas, G. (2018), "Persuasive technologies for sustainable mobility: state of the art and emerging trends", Sustainability, Vol. 10 No. 7, p. 2128.

Attig, C. and Franke, T. (2018), "I track, therefore I walk Đ exploring the motivational costs of wearing activity trackers in actual users", International Journal of Human-Computer Studies, Vol. 127, pp. 211-224.

Baptista, G. and Oliveira, T. (2017), "Why so serious? Gamification impact in the acceptance of mobile banking services", Internet Research, Vol. 27 No. 1, pp. 118-139.

Bartoli, E., Elmi, B., Pascuzzi, D. and Smorti, A. (2018), "Gamification in tourism”, Psychology and Behavioral Sciences, Vol. 8 No. 3, pp. 93-95.

Bernardi, M. (2015), Un’introduzione Alla Sharing Economy, Ebook, Fondazione GianGiacomo Feltrinelli, Milano.

Bogost, I. (2007), Persuasive Games, Vol. 5, MIT Press, Cambridge, MA.

Bonde, M.T., Makransky, G., Wandall, J., Larsen, M.V., Morsing, M., Jarmer, H. and Sommer, M.O. (2014), "Improving biotech education through gamified laboratory simulations", Nature Biotechnology, Vol. 32 No. 7, pp. 694-697.

Breidbach, C.F. and Brodie, R.J. (2017), "Engagement platforms in the sharing economy", Journal of Service Theory and Practice, Vol. 27 No. 4, pp. 761-777.

Breidbach, C.F., Brodie, R. and Hollebeek, L. (2014), "Beyond virtuality: from engagement platforms to engagement ecosystems", Managing Service Quality: an International Journal, Vol. 24 No. 6, pp. 592-611.

Brigham, T.J. (2015), "An introduction to gamification: adding game elements for engagement", Medical Reference Services Quarterly, Vol. 34 No. 4, pp. 471-480.

Buckley, P., Noonan, S., Geary, C., Mackessy, T. and Nagle, E. (2019), “An empirical study of gamification frameworks", Journal of Organizational and End User Computing, Vol. 31 No. 1, pp. 22-38.

Budeanu, A. (2007), "Sustainable tourist behavior-a discussion of opportunities for change", International Journal of Consumer Studies, Vol. 31 No. 5, pp. 499-508.

Buhalis, D. and Wagner, R. (2013), "E-destinations: global best practice in tourism technologies and applications", Information and Communication Technologies in Tourism 2013, Springer, Berlin and Heidelberg, pp. 119-130.

Buhalis, D., Harwood, T., Bogicevic, V., Viglia, G., Beldona, S. and Hofacker, C. (2019), "Technological disruptions in services: lessons from tourism and hospitality", Journal of Service Management, Vol. 30 No. 4, pp. 484-506.

Cantallops, A.S. and Salvi, F. (2014), "New consumer behavior: a review of research on eWOM and hotels", International Journal of Hospitality Management, Vol. 36, pp. 41-51.

Chen, J.S. (2015), "Tourism stakeholders attitudes toward sustainable development: a case in the Arctic", Journal of Retailing and Consumer Services, Vol. 22, pp. 225-230.

Cheong, C., Cheong, F. and Filippou, J. (2013), "Quick quiz: a gamified approach for enhancing learning", PACIS, p. 206, June.

Christy, K.R. and Fox, J. (2014), "Leader boards in a virtual classroom: a test of stereotype threat and social comparison explanations for women's math performance", Computers and Education, Vol. 78, pp. 66-77.

Gamification in tourism and hospitality

\section{$-$}


JSTP 31,5
Conaway, R. and Garay, M.C. (2014), "Gamification and service marketing", SpringerPlus, Vol. 3 No. 1, pp. 1-11.

Cooper, H. (1989), "Synthesis of research on homework", Educational Leadership, Vol. 47 No. 3, pp. 85-91.

Correa, C. and Kitano, C. (2015), "Gamification in tourism: analysis of Brazil quest game", e-Review of Tourism Research, Vol. 6 No. 1, pp. 1-5.

de Oliveira Nunes, M. and Mayer, V.F. (2014), "Mobile technology, games and nature areas: the tourist perspective", Tourism and Management Studies, Vol. 10 No. 1, pp. 53-58.

Deci, E.L. and Ryan, R.M. (1985), Cognitive Evaluation Theory. Intrinsic Motivation and SelfDetermination in Human Behavior, Springer US, Boston, MA, pp. 43-85.

Denyer, D. and Tranfield, D. (2009), Producing a Systematic Review.

Deterding, S. (2015), "The lens of intrinsic skill atoms: a method for gameful design", HumanComputer Interaction, Vol. 30 Nos 3-4, pp. 294-335.

Deterding, S. (2019), "Gamification in management: between choice architecture and humanistic design”, Journal of Management Inquiry, Vol. 28 No. 2, pp. 131-136.

Deterding, S., Dixon, D., Khaled, R. and Nacke, L. (2011), "From game design elements to gamefulness: defining gamification", Proceedings of the 15th International Academic MindTrek Conference: Envisioning Future Media Environments, ACM, Tampere, pp. 9-15.

Dicheva, D., Dichev, C., Agre, G. and Angelova, G. (2015), "Gamification in education: a systematic mapping study", Journal of Educational Technology and Society, Vol. 18 No. 3, pp. 75-88.

Dief, M.E. and Font, X. (2010), “The determinants of hotels' marketing managers' green marketing behavior", Journal of Sustainable Tourism, Vol. 18 No. 2, pp. 157-174.

Diefenbach, S. and Mussig (2018), "Counterproductive effects of gamification: analysis on the example of the gamified task manager Habitica", International Journal of Human-Computer Studies, Vol. 127, pp. 190-210.

Dingli, A. and Mizzi, D. (2018), "Gamifying history using beacons and mobile technologies", Interactive Mobile Communication, Technologies and Learning, Springer, Cham, pp. 151-162, October.

DomíNguez, A., Saenz-De-Navarrete, J., De-Marcos, L., FernáNdez-Sanz, L., PagéS, C. and MartíNezHerrálz, J.J. (2013), "Gamifying learning experiences: practical implications and outcomes", Computers and Education, Vol. 63, pp. 380-392.

Donthu, N., Kumar, S., Ranaweera, C., Sigala, M. and Sureka, R. (2021), "Journal of Service Theory and Practice at age 30: past, present and future contributions to service research", Journal of Service Theory and Practice, Vol. 31 No. 3, pp. 265-295.

Dorcic, J., Komsic, J. and Markovic, S. (2019), "Mobile technologies and applications towards smart tourism - state of the art", Tourism Review, Vol. 74 No. 1, pp. 82-103.

Fischöder, N., Iurgel, I.A., Sezen, T.I. and van Turnhout, K. (2018), “A storytelling smart-city approach to further cross-regional tourism", Interactivity, Game Creation, Design, Learning, and Innovation, Springer, Cham, pp. 266-275.

Fleming, T.M., Bavin, L., Stasiak, K., Hermansson-Webb, E., Merry, S.N., Cheek, C., Lucassen, M., Lau Ho, M., Pollmuller, B. and Hetrick, S. (2017), "Serious games and gamification for mental health: current status and promising directions", Frontiers in Psychiatry, Vol. 7, p. 215.

Følstad, A. and Kvale, K. (2018), "Customer journeys: a systematic literature review", Journal of Service Theory and Practice, Vol. 28 No. 2, pp. 196-227.

Galvagno, M., Dalli, D. and Galvagno, M. (2014), "Theory of value co-creation: a systematic literature review”, Marketing Service Quality, Vol. 24 No. 6, pp. 643-683.

Garcia, A., Linaza, M.T., Gutierrez, A. and Garcia, E. (2019), "Gamified mobile experiences: smart technologies for tourism destinations”, Tourism Review, Vol. 74 No. 1, pp. 30-49. 
Garett, R. and Young, S.D. (2019), "Health care gamification: a study of game mechanics and Gamification in elements", Technology, Knowledge and Learning, Vol. 24 No. 3, pp. 341-353.

Gentry, S., L’Estrade Ehrstrom, B., Gauthier, A., Alvarez, J., Wortley, D., van Rijswijk, J., Car, J., Lilienthal, A., Tudor Car, L., Nikolaou, C.K. and Zary, N. (2018), "Serious gaming and gamification interventions for health professional education", The Cochrane Database of Systematic Reviews, Vol. 2018 No. 6, CD012209, doi: 10.1002/14651858.CD012209.pub2.

Gera, K. and Hasdell, P. (2019), "Gamified sharing economy: the role of game elements in sharing economy", International Conference on Applied Human Factors and Ergonomics, Springer, Cham, pp. 232-242, July.

Grönroos, C. (2007), Service Management and Marketing: Customer Management in Service Competition, John Wiley \& Sons, Chichester.

Guerreiro, J. and Moro, S. (2017), “Are Yelp's tips helpful in building influential consumers?”, Tourism Management Perspectives, Vol. 24, pp. 151-154.

Hamari, J. (2013), "Transforming homo economicus into homo ludens: a field experiment on gamification in a utilitarian peer-to-peer trading service", Electronic Commerce Research and Applications, Vol. 12 No. 4, pp. 236-245.

Hamari, J. (2017), "Do badges increase user activity? A field experiment on the effects of gamification", Computers in Human Behavior, Vol. 71, pp. 469-478.

Hamari, J. and Eranti, V. (2011), "Framework for designing and evaluating game achievements”, Digra Conference.

Hamari, J. and Keronen, L. (2017), "Why do people play games? A meta-analysis”, International Journal of Information Management, Vol. 37 No. 3, pp. 125-141.

Hamari, J. and Koivisto, J. (2015), “Why do people use gamification services?”, International Journal of Information Management, Vol. 35 No. 4, pp. 419-431.

Hamari, J., Koivisto, J. and Pakkanen, T. (2014a), "Do persuasive technologies persuade? A review of empirical studies", International Conference on Persuasive Technology, Springer, Cham, pp. 118-136.

Hamari, J., Koivisto, J. and Sarsa, H. (2014b), "Does gamification work? A literature review of empirical studies on gamification", HICSS, Vol. 14, pp. 3025-3034.

Hammedi, W., Leclerq, T. and Van Riel, A.C. (2017), "The use of gamification mechanics to increase employee and user engagement in participative healthcare services", Journal of Service Management, Vol. 28 No. 4, pp. 640-661.

Hannigan, J. (1998), Fantasy City: Pleasure and Profit in the Postmodern Metropolis, Routledge, London and New York.

Heinonen, K., Jaakkola, E. and Neganova, I. (2018), "Drivers, types and value outcomes of customer-tocustomer interaction: an integrative review and research agenda", Journal of Service Theory and Practice, Vol. 28 No. 6, pp. 710-732.

Helmefalk, M. (2019), "An interdisciplinary perspective on gamification: mechanics, psychological mediators and outcomes", International Journal of Serious Games, Vol. 6 No. 1, pp. 3-26.

Hertzman, E., Anderson, D. and Rowley, S. (2008), "Edutainment heritage tourist attractions: a portrait of visitors' experiences at storyeum", Museum Management and Curatorship, Vol. 23 No. 2, pp. 155-175.

Hsu, C.L. and Chen, M.C. (2018), "How does gamification improve user experience? An empirical investigation on the antecedences and consequences of user experience and its mediating role", Technological Forecasting and Social Change, Vol. 132, pp. 118-129.

Huang, B., Hew, K.F. and Lo, C.K. (2019), "Investigating the effects of gamification-enhanced flipped learning on undergraduate students' behavioral and cognitive engagement”, Interactive Learning Environments, Vol. 27 No. 8, pp. 1106-1126.

Huotari, K. and Hamari, J. (2012), "Defining gamification: a service marketing perspective”, Proceeding of the 16th International Academic MindTrek Conference, ACM, Tampere, pp. 17-22. 
JSTP 31,5
Huotari, K. and Hamari, J. (2017), "A definition for gamification: anchoring gamification in the service marketing literature”, Electronic Markets, Vol. 27 No. 1, pp. 21-31.

Hyrynsalmi, S., Smed, J. and Kimppa, K. (2017), "The dark side of gamification: how we should stop worrying and study also the negative impacts of bringing game design elements to everywhere", GamiFIN, May, pp. 96-104.

Ip, C., Law, R. and Lee, H.A. (2011), "A review of website evaluation studies in the tourism and hospitality fields from 1996 to 2009", International Journal of Tourism Research, Vol. 13 No. 3, pp. 234-265.

Ipeirotis, P.G. and Gabrilovich, E. (2014), "Quizz: targeted crowdsourcing with a billion (potential) users", Proceedings of the 23rd International Conference on World Wide Web, pp. 143-154, April.

Jakobsson, M. (2011), "The achievement machine: understanding Xbox 360 achievements in gaming practices", Game Studies, Vol. 11 No. 1, pp. 1-22.

Johnson, D., Deterding, S., Kuhn, K.A., Staneva, A., Stoyanov, S. and Hides, L. (2016), “Gamification for health and wellbeing: a systematic review of the literature", Internet Interventions, Vol. 6, pp. 89-106.

Jones, B.A., Madden, G.J. and Wengreen, H.J. (2014), "The FIT game: preliminary evaluation of a gamification approach to increasing fruit and vegetable consumption in school", Preventive Medicine, Vol. 68, pp. 76-79.

Kachniewska, M. (2015), "Gamification and social media as tools for tourism promotion", Handbook of Research on Effective Advertising Strategies in the Social Media Age, IGI Global, Hershey, PA, pp. 17-51.

Kalafatis, S.P. and Pollard, M. (1999), "Green marketing and Ajzens theory of planned behavior, a cross market examination”, Journal of Consumer Marketing, Vol. 16, pp. 441-461.

Kankanhalli, A., Taher, M., Cavusoglu, H. and Kim, S.H. (2012), "Gamification: a new paradigm for online user engagement", International Conference on Information Systems, Orlando, 2012.

Kapoor, A.J., Lepore, B., Segal, J. and Kurinsky, M. (2020), Gamification to Educate on Combined Sewer Overflows and Improve Water Conservation.

Kapp, K.M. (2012), The Gamification of Learning and Instruction: Game-Based Methods and Strategies for Training and Education, John Wiley and Sons, San Francisco, CA.

Kapp, K.M. (2013), The Gamification of Learning and Instruction Fieldbook: Ideas into Practice, John Wiley and Sons, San Francisco.

Kelman, H.C. (1958), "Compliance, identification, and internalization three processes of attitude change", Journal of Conflict Resolution, Vol. 2 No. 1, pp. 51-60.

Kim, S., Song, K., Lockee, B. and Burton, J. (2018), "What is gamification in learning and education?", in Gamification in Learning and Education, Springer, Cham, pp. 25-38.

Királová, A. (2015), "The place of gamification in tourism destinations' marketing. IDIMT-2015 Information Technology and Society Interaction and Interdependence", 23rd Interdisciplinary Information Management Talks, Schriftreihe Informatik, Hershey, PA, Vol. 44, pp. 163-173.

Kitchenham, B., Brereton, O.P., Budgen, D., Turner, M., Bailey, J. and Linkman, S. (2008), "Systematic literature reviews in software engineering-a systematic literature review", Information and Software Technology, Vol. 51 No. 1, pp. 7-15.

Klock, A.C.T., Gasparini, I., Pimenta, M.S. and Hamari, J. (2020), “Tailored gamification: a review of literature", International Journal of Human-Computer Studies, Vol. 144, p. 102495.

Koivisto, J. and Hamari, J. (2019), "The rise of motivational information systems: a review of gamification research", International Journal of Information Management, Vol. 45, pp. 191-210.

Konig, A., Kowala, N., Wegener, J. and Grippenkoven, J. (2019), "Introducing a mobility on demand system to prospective users with the help of a serious game", Transportation Research Interdisciplinary Perspectives, Vol. 3, p. 100079. 
Kumar, A., Bezawada, R., Rishika, R., Janakiraman, R. and Kannan, P.K. (2016), "From social to sale: the effects of firm-generated content in social media on customer behavior", Journal of Marketing, Vol. 80 No. 1, pp. 7-25.

Larson, K. (2020), "Serious games and gamification in the corporate training environment: a literature review", TechTrends, Vol. 64 No. 2, pp. 319-328.

Leclercq, T., Hammedi, W. and Poncin, I. (2018), "The boundaries of gamification for engaging customers: effects of losing a contest in online co-creation communities", Journal of Interactive Marketing, Vol. 44, pp. 82-101.

Lee, B.C. (2019), "The effect of gamification on psychological and behavioral outcomes: implications for cruise tourism destinations", Sustainability, Vol. 11 No. 11, p. 3002.

Lee, J.J., Ceyhan, P., Jordan-Cooley, W. and Sung, W. (2013), "GREENIFY: a real-world action game for climate change education", Simulation and Gaming, Vol. 44 Nos 2-3, pp. 349-365.

Liang, S., Schuckert, M., Law, R. and Chen, C.C. (2017), "Be a "Superhost": the importance of badge systems for peer-to-peer rental accommodations", Tourism Management, Vol. 60, pp. 454-465.

Liang, S., Schuckert, M., Law, R. and Chen, C.C. (2020), "The importance of marketer-generated content to peer-to-peer property rental platforms: evidence from Airbnb", International Journal of Hospitality Management, Vol. 84, p. 102329.

Lim, K.H., Chan, J., Leckie, C. and Karunasekera, S. (2015), "Personalized tour recommendation based on user interests and points of interest visit durations", Twenty-Fourth International Joint Conference on Artificial Intelligence, June.

Lin, C.P. and Bhattacherjee, A. (2008), "Elucidating individual intention to use interactive information technologies: the role of network externalities", International Journal of Electronic Commerce, Vol. 13 No. 1, pp. 85-108.

Lounis, S., Pramatari, K. and Theotokis, A. (2014), "Gamification is all about fun: the role of incentive type and community collaboration”, ECIS.

Lu, V.N., Wirtz, J., Kunz, W.H., Paluch, S., Gruber, T., Martins, A. and Patterson, P.G. (2020), "Service robots, customers and service employees: what can we learn from the academic literature and where are the gaps?", Journal of Service Theory and Practice, Vol. 30 No. 3, pp. 361-391.

MacInnis, D.J. (2011), “A framework for conceptual contributions in marketing”, Journal of Marketing, Vol. 75 No. 4, pp. 136-154.

Macke, J. and Genari, D. (2019), "Systematic literature review on sustainable human resource management", Journal of Cleaner Production, Vol. 208, pp. 806-815.

Macdonald, S.A. and Brewster, S. (2019), "Gamification of a to-do list with emotional reinforcement", Extended Abstracts of the 2019 CHI Conference on Human Factors in Computing Systems, pp. 1-6, May.

Mair, J. and Laing, J.H. (2013), "Encouraging pro-environmental behavior: the role of sustainabilityfocused events", Journal of Sustainable Tourism, Vol. 21 No. 8, pp. 1113-1128.

Majuri, J., Koivisto, J. and Hamari, J. (2018), "Gamification of education and learning: a review of empirical literature", Proceedings of the 2nd International GamiFIN Conference, GamiFIN 2018, CEUR-WS, Pori.

Mantouka, E.G., Barmpounakis, E.N., Milioti, C.P. and Vlahogianni, E.I. (2019), "Gamification in mobile applications: the case of airports", Journal of Intelligent Transportation Systems, Vol. 23 No. 5, pp. 417-426.

Marconi, A., Schiavo, G., Zancanaro, M., Valetto, G. and Pistore, M. (2018), "Exploring the world through small green steps: improving sustainable school transportation with a game-based learning interface", Proceedings of the 2018 International Conference on Advanced Visual Interfaces, pp. 1-9, May.

Gamification in tourism and hospitality 
JSTP 31,5

Mariani, M., Baggio, R., Fuchs, M. and Höepken, W. (2018), "Business intelligence and big data in hospitality and tourism: a systematic literature review", International Journal of Contemporary Hospitality Management, Vol. 30 No. 12, pp. 3514-3554.

Markouzis, D. and Fessakis, G. (2015), “'Interactive storytelling and mobile augmented reality applications for learning and entertainment - a rapid prototyping perspective", International Conference on Interactive Mobile Communication Technologies and Learning (IMCL), IEEE, Thessaloniki, pp. 4-8.

Mesáro, P., Mandičák, T., Hernandez, M.F., Sido, C., Molokáč, M., Hvizdák, L. and Delina, R. (2016), "Use of augmented reality and gamification techniques in tourism", E-review of Tourism Research, Vol. 13 Nos 1-2, pp. 366-381.

Moher, D., Liberati, A., Tetzlaff, J. and Altman, D.G. (2009), "Preferred reporting items for systematic reviews and meta-analyses: the PRISMA statement", Annals of Internal Medicine, Vol. 151 No. 4, pp. 264-269.

Morganti, L., Pallavicini, F., Cadel, E., Candelieri, A., Archetti, F. and Mantovani, F. (2017), "Gaming for Earth: serious games and gamification to engage consumers in pro-environmental behaviors for energy efficiency", Energy Research and Social Science, Vol. 29, pp. 95-102.

Moro, S., Rita, P. and Oliveira, C. (2018), "Factors influencing hotels' online prices", Journal of Hospitality Marketing and Management, Vol. 27 No. 4, pp. 443-464.

Moro, S., Ramos, P., Esmerado, J. and Jalali, S.M.J. (2019), "Can we trace back hotel online reviews' characteristics using gamification features?", International Journal of Information Management, Vol. 44, pp. 88-95.

Morschheuser, B., Hamari, J. and Koivisto, J. (2016), "Gamification in crowdsourcing: a review", 2016 49th Hawaii International Conference on System Sciences (HICSS), IEEE, Koloa, HI, pp. 4375-4384, January.

Mulcahy, R.F., Russell-Bennett, R., Zainuddin, N. and Kuhn, K.A. (2018), "Designing gamified transformative and social marketing services”, Journal of Service Theory and Practice, Vol. 28 No. 1, pp. 26-51.

Mulcahy, R.F., Zainuddin, N. and Russell-Bennett, R. (2020), "Transformative value and the role of involvement in gamification and serious games for well-being", Journal of Service Management, Vol. 32 No. 2, pp. 218-245.

Negruşa, A.L., Toader, V., Sofică, A., Tutunea, M.F. and Rus, R.V. (2015), "Exploring gamification techniques and applications for sustainable tourism", Sustainability, Vol. 7 No. 8, pp. 11160-11189.

Neuhofer, B., Buhalis, D. and Ladkin, A. (2012), "Conceptualising technology enhanced destination experiences”, Journal of Destination Marketing and Management, Vol. 1 Nos 1-2, pp. 36-46.

Olszewski, R. and Turek, A. (2020), "The mordor shaper-the warsaw participatory experiment using gamification", ICT Systems and Sustainability, Springer, Singapore, pp. 255-264.

Paré, G., Trudel, M.C., Jaana, M. and Kitsiou, S. (2015), "Synthesizing information systems knowledge: a typology of literature reviews", Information and Management, Vol. 52 No. 2, pp. 183-199.

Patrício, R., Moreira, A.C. and Zurlo, F. (2018), "Gamification approaches to the early stage of innovation”, Creativity and Innovation Management, Vol. 27 No. 4, pp. 499-511.

Patricio, R., Moreira, A., Zurlo, F. and Melazzini, M. (2020), "Co-creation of new solutions through gamification: a collaborative innovation practice", Creativity and Innovation Management, Vol. 29 No. 1, pp. 146-160.

Paulauskaite, D., Powell, R., Coca-Stefaniak, J.A. and Morrison, A.M. (2017), "Living like a local: authentic tourism experiences and the sharing economy", International Journal of Tourism Research, Vol. 19 No. 6, pp. 619-628.

Phillips, P. and Moutinho, L. (2014), "Critical review of strategic planning research in hospitality and tourism”, Annals of Tourism Research, Vol. 48, pp. 96-120. 
Pickering, C. and Byrne, J. (2013), "The benefits of publishing systematic quantitative literature reviews for $\mathrm{PhD}$ candidates and other early-career researchers", Higher Education Research and Development, Vol. 33, pp. 534-548.

Pickering, C. and Byrne, J. (2014), "The benefits of publishing systematic quantitative literature reviews for $\mathrm{PhD}$ candidates and other early-career researchers", Higher Education Research and Development, Vol. 33 No. 3, pp. 534-548.

Pickering, C., Grignon, J., Steven, R., Guitart, D. and Byrne, J. (2015), "Publishing not perishing: how research students transition from novice to knowledgeable using systematic quantitative literature reviews", Studies in Higher Education, Vol. 40 No. 10, pp. 1756-1769.

Pine, B.J. and Gilmore, J.H. (1999), The Experience Economy, Harvard Business School Press, Boston.

Poria, Y., Butler, R. and Airey, D. (2003), "Tourism, religion and religiosity: a holy mess", Current Issues in Tourism, Vol. 6 No. 4, pp. 340-363.

Rajanen, D. and Rajanen, M. (2019), "Climate change gamification: a literature review”, GamiFIN, pp. 253-264.

Ramos, C.M., Henriques, C. and Lanquar, R. (2016), "Augmented reality for smart tourism in religious heritage itineraries: tourism experiences in the technological age", Handbook of Research on Human-Computer Interfaces, Developments, and Applications, IGI Global, Hershey, PA, pp. 245-272.

Rapp, A., Cena, F., Hopfgartner, F., Hamari, J. and Linehan, C. (2016), "Fictional game elements: critical perspectives on gamification design", Proceedings of the 2016 Annual Symposium on Computer-Human Interaction in Play Companion Extended Abstracts (CHI PLAY Companion '16), ACM, New York, pp. 373-377.

Rapp, A., Hopfgartner, F., Hamari, J., Linehan, C. and Cena, F. (2018), "Strengthening gamification studies: current trends and future opportunities of gamification research", International Journal of Human-Computer Studies, Vol. 127, pp. 1-6.

Reportlinker (2018), "Global gamification market by solution, by deployment, by organization size, by application, by end-user vertical, by region, competition, forecast and opportunities, 2024", available at: https://www.reportlinker.com/p05762137/Global-Gamification-Market-By-SolutionBy-Deployment-By-Organization-Size-By-Application-By-End-User-Vertical-By-RegionCompetition-Forecast-Opportunities.html?utm_source=PRN (accessed February).

Resnick, P. and Zeckhauser, R. (2002), "Trust among strangers in internet transactions: empirical analysis of eBay's reputation system", The Economics of the Internet and e-Commerce, Vol. 11 No. 2, pp. 23-25.

Richter, G., Raban, D.R. and Rafaeli, S. (2015), "Studying gamification: the effect of rewards and incentives on motivation", Gamification in Education and Business, Springer, Cham, pp. 21-46.

Ritterfeld, U., Cody, M. and Vorderer, P. (Eds) (2009), Serious Games: Mechanisms and Effects, Routledge, New York.

Robson, K., Plangger, K., Kietzmann, J.H., McCarthy, I. and Pitt, L. (2015), "Is it all a game? Understanding the principles of gamification”, Business Horizons, Vol. 58 No. 4, pp. 411-420.

Ruhanen, L., Weiler, B., Moyle, B.D. and McLennan, C.L.J. (2015), "Trends and patterns in sustainable tourism research: a 25-year bibliometric analysis", Journal of Sustainable Tourism, Vol. 23 No. 4, pp. 517-535.

Ryan, R.M. and Deci, E.L. (2000a), "Self-determination theory and the facilitation of intrinsic motivation, social development, and well-being”, American Psychologist, Vol. 55, pp. 68-78.

Ryan, R.M. and Deci, E.L. (2011), "A self-determination theory perspective on social, institutional, cultural, and economic supports for autonomy and their importance for well-being", Human Autonomy in Cross-Cultural Context, Springer, Dordrecht, pp. 45-64.

Ryu, J.H., Park, J.W., Nahm, F.S., Jeon, Y.T., Oh, A.Y., Lee, H.J., Kim, J.H. and Han, S.H. (2018), “The effect of gamification through a virtual reality on preoperative anxiety in paediatric patients 
JSTP 31,5

undergoing general anaesthesia: a prospective, randomized, and controlled trial", Journal of Clinical Medicine, Vol. 7 No. 9, p. 284.

Sailer, M., Hense, J.U., Mayr, S.K. and Mandl, H. (2017), "How gamification motivates: an experimental study of the effects of specific game design elements on psychological need satisfaction", Computers in Human Behavior, Vol. 69, pp. 371-380.

Schmidt-Kraepelin, M., Thiebes, S., Stepanovic, S., Mettler, T. and Sunyaev, A. (2019), "Gamification in health behavior change support systems-A synthesis of unintended side effects", Proceedings of the 14th International Conference on Wirtschaftsinformatik, pp. 1032-1046.

Schuckert, M., Liu, X. and Law, R. (2015), "Hospitality and tourism online reviews: recent trends and future directions", Journal of Travel and Tourism Marketing, Vol. 32 No. 5, pp. 608-621.

Schuckert, M., Liu, X. and Law, R. (2016), "Stars, votes, and badges: how online badges affect hotel reviewers", Journal of Travel and Tourism Marketing, Vol. 33 No. 4, pp. 440-452.

Séraphin, H., Butcher, J. and Korstanje, M. (2017), "Challenging the negative images of Haiti at a previsit stage using visual online learning materials", Journal of Policy Research in Tourism, Leisure and Events, Vol. 9 No. 2, pp. 169-181.

Seaborn, K. and Fels, D.I. (2015), "Gamification in theory and action: a survey", International Journal of Human-Computer Studies, Vol. 74, pp. 14-31.

Séraphin, H. (2019), "Marketing and diaspora tourism: visual online learning materials as tools to attract the Haitian diaspora 'new generation", Diaspora Networks in International Business, Springer, Cham, pp. 493-510.

Shen, Y. and Joppe, M. (2019), "Gamification in tourism advertising: game mechanics and practices", e-Review of Tourism Research, available at: https://journals.tdl.org/ertr/index.php/ertr/article/ view/124 (accessed 22 April 2021).

Sigala, M. (2007), "Integrating web 2.0 in e-learning environments: a socio-technical approach", International Journal of Knowledge and Learning, Vol. 3 No. 6, p. 628.

Sigala, M. (2015a), "Applying gamification and assessing its effectiveness in a tourism context: behavioral and psychological outcomes of the Tripadvisor's gamification users", Asia Pacific Journal of Information Systems, Vol. 25 No. 1, pp. 179-210.

Sigala, M. (2015b), "The application and impact of gamification funware on trip planning and experiences: the case of Tripadvisor's funware”, Electronic Markets, Vol. 25 No. 3, pp. 189-209.

Sigala, M. (2015c), "Gamification for crowdsourcing marketing practices: applications and benefits in tourism", Advances in Crowdsourcing, Springer, Cham, pp. 129-145.

Sigala, M. (2018), "Implementing social customer relationship management", International Journal of Contemporary Hospitality Management, Vol. 30 No. 7, pp. 2698-2726.

Sigala, M. (2020), "Tourism and COVID-19: impacts and implications for advancing and resetting industry and research", Journal of Business Research, Vol. 117, pp. 312-321.

Sigala, M., Toni, M., Renzi, M.F., Di Pietro, L. and Mugion, R.G. (2019), "Gamification in Airbnb: benefits and risks", e-Review of Tourism Research, Vol. 16 Nos 2/3.

Skinner, H., Sarpong, D. and White, G.R. (2018), "Meeting the needs of the Millennials and Generation Z: gamification in tourism through geocaching", Journal of Tourism Futures, Vol. 4 No. 1, pp. 93-104.

Snyder, H. (2019), "Literature review as a research methodology: an overview and guidelines", Journal of Business Research, Vol. 104, pp. 333-339.

Sparks, B.A. and Browning, V. (2011), "The impact of online reviews on hotel booking intentions and perception of trust”, Tourism Management, Vol. 32 No. 6, pp. 1310-1323.

$\mathrm{Su}, \mathrm{C} . \mathrm{H}$. and Cheng, C.H. (2015), "A mobile gamification learning system for improving the learning motivation and achievements", Journal of Computer Assisted Learning, Vol. 31 No. 3, pp. 268-286. 
Suh, A., Wagner, C. and Liu, L. (2015), "The effects of game dynamics on user engagement in gamified systems", 2015 48th Hawaii International Conference on System Sciences, IEEE, Kauai, HI, pp. 672-681, January.

Susi, T., Johannesson, M. and Backlund, P. (2007), Serious Games: An Overview.

Gamification in tourism and hospitality

Swacha, J. and Ittermann, R. (2017), "Enhancing the tourist attraction visiting process with gamification: key concepts", Engineering Management in Production and Services, Vol. 9 No. 4, pp. 59-66.

Tan, W.K. (2018), "Gamification in aquarium context Intention to play game that imparts knowledge and promotes marine animal conservation", Information Technology and People, Vol. 31 No. 6, pp. 1070-1090.

Terlutter, R. and Capella, M.L. (2013), "The gamification of advertising: analysis and research directions of in-game advertising, advergames, and advertising in social network games", Journal of advertising, Vol. 42 Nos 2-3, pp. 95-112.

Thiebes, S., Lins, S. and Basten, D. (2014), "Gamifying information systems-a synthesis of gamification mechanics and dynamics", European Conference on Information Systems.

Tobon, S., Ruiz-Alba, J.L. and García-Madariaga, J. (2020), "Gamification and online consumer decisions: is the game over?", Decision Support Systems, Vol. 128, p. 113167.

Toda, A.M., Valle, P.H. and Isotani, S. (2017), "The dark side of gamification: an overview of negative effects of gamification in education", in Researcher Links Workshop: Higher Education for All, Springer, Cham, pp. 143-156, March.

Tranfield, D., Denyer, D. and Smart, P. (2003), "Towards a methodology for developing evidenceinformed management knowledge by means of systematic review", British Journal of Management, Vol. 14 No. 3, pp. 207-222.

Tsai, T.H. and Lee, L.C. (2017), "Location-based augmented reality for exploration of cultural heritage", ICIC Express Letters. Part B, Applications: An International Journal of Research and Surveys, Vol. 8 No. 12, pp. 1577-1583.

Tsay, C.H.H., Kofinas, A. and Luo, J. (2018), "Enhancing student learning experience with technologymediated gamification: an empirical study", Computers and Education, Vol. 121, pp. 1-17.

Tussyadiah, I.P. and Fesenmaier, D.R. (2009), "Mediating tourist experiences: access to places via shared videos", Annals of Tourism Research, Vol. 36 No. 1, pp. 24-40.

UNWTO (2020), UNWTO World Tourism Barometer, UNWTO, Madrid, Vol. 18.

Van der Heijden, H. (2004), "User acceptance of hedonic information systems”, MIS Quarterly, Vol. 28 No. 4, pp. 695-704.

Van Roy, R. and Zaman, B. (2018), "Need-supporting gamification in education: an assessment of motivational effects over time", Computers and Education, Vol. 127, pp. 283-297.

Vargo, S.L. and Lusch, R.F. (2008), "Service-dominant logic: continuing the evolution", Journal of the Academy of Marketing Science, Vol. 36 No. 1, pp. 1-10.

Venkatesh, V. and Davis, F.D. (2000), "A theoretical extension of the technology acceptance model: four longitudinal field studies", Management Science, Vol. 46 No. 2, pp. 186-204.

Verplanken, B. and Wood, W. (2006), "Interventions to break and create consumer habits", Journal of Public Policy and Marketing, Vol. 25 No. 1, pp. 90-103.

Wang, Y., Han, J.H. and Beynon-Davies, P. (2019), "Understanding blockchain technology for future supply chains: a systematic literature review and research agenda", Supply Chain Management: An International Journal, Vol. 24 No. 1, pp. 62-84.

Warmelink, H., Koivisto, J., Mayer, I., Hamari, J. and Vesa, M. (2018), "Gamification of the work floor: a literature review of gamifying production and logistics operations", Proceedings of the 51st Annual Hawaï International Conference on System Sciences (HICSS), Hawaii International Conference on System Sciences, Waikoloa Village, Hawaii. 
JSTP 31,5
Warmelink, H., Koivisto, J., Mayer, I., Vesa, M. and Hamari, J. (2020), "Gamification of production and logistics operations: status quo and future directions", Journal of Business Research, Vol. 106, pp. 331-340.

Wasan, P. (2017), "Managing technologies for consumer engagement", Hospitality Marketing and Consumer Behavior: Creating Memorable Experiences.

Webster, J. and Watson, R.T. (2002), "Analyzing the past to prepare for the future: writing a literature review”, MIS Quarterly, Vol. 26 No. 2, pp. 13-23.

Weiler, B., Moyle, B. and McLennan, C.L. (2012), "Disciplines that influence tourism doctoral research: the United States, Canada, Australia and New Zealand", Annals of Tourism Research, Vol. 39 No. 3, pp. 1425-1445.

Werbach, K. and Hunter, D. (2012), For the Win: How Game Thinking Can Revolutionize Your Business, Wharton Digital Press, Philadelphia, PA.

Wünderlich, N.V., Gustafsson, A., Hamari, J., Parvinen, P. and Haff, A. (2020), "The great game of business: advancing knowledge on gamification in business contexts", Journal of Business Research, Vol. 106, pp. 273-276.

Xi, N. and Hamari, J. (2019), "Does gamification satisfy needs? A study on the relationship between gamification features and intrinsic need satisfaction", International Journal of Information Management, Vol. 46, pp. 210-221.

Xi, N. and Hamari, J. (2020), "Does gamification affect brand engagement and equity? A study in online brand communities", Journal of Business Research, Vol. 109, pp. 449-460.

Xu, Y. (2011), Literature Review on Web Application Gamification and Analytics, Honolulu, HI, pp. 11-05.

$\mathrm{Xu}, \mathrm{F}$., Weber, J. and Buhalis, D. (2013), "Gamification in tourism”, Information and Communication Technologies in Tourism, Springer, Cham, pp. 525-537.

$\mathrm{Xu}, \mathrm{F}$., Weber, J. and Buhalis, D. (2014), "Gamification in tourism", Information and Communication Technologies in Tourism 2014, Springer, Cham, pp. 525-537.

Xu, C., Peak, D. and Prybutok, V. (2015), "A customer value, satisfaction, and loyalty perspective of mobile application recommendations", Decision Support Systems, Vol. 79, pp. 171-183.

Xu, F., Tian, F., Buhalis, D., Weber, J. and Zhang, H. (2016), "Tourists as mobile gamers: gamification for tourism marketing", Journal of Travel and Tourism Marketing, Vol. 33 No. 8, pp. 1124-1142.

Xu, F., Buhalis, D. and Weber, J. (2017), "Serious games and the gamification of tourism", Tourism Management, Vol. 60, pp. 244-256.

Yang, E.C.L., Khoo-Lattimore, C. and Arcodia, C. (2017), "A systematic literature review of risk and gender research in tourism”, Tourism Management, Vol. 58, pp. 89-100.

Yang, C.C., Sia, W.Y., Tseng, Y.C. and Chiu, J.C. (2018), "Gamification of learning in tourism industry: a case study of Pokémon Go", Proceedings of the 2018 2nd International Conference on Education and E-Learning, pp. 191-195, November.

Ye, Q., Law, R. and Gu, B. (2009), "The impact of online user reviews on hotel room sales", International Journal of Hospitality Management, Vol. 28 No. 1, pp. 180-182.

Yoo, C., Kwon, S., Na, H. and Chang, B. (2017), "Factors affecting the adoption of gamified smart tourism applications: an integrative approach”, Sustainability, Vol. 9 No. 12, p. 2162.

Yung, R. and Khoo-Lattimore, C. (2019), "New realities: a systematic literature review on virtual reality and augmented reality in tourism research", Current Issues in Tourism, Vol. 22 No. 17, pp. 2056-2081.

Zainuddin, Z., Chu, S.K.W., Shujahat, M. and Perera, C.J. (2020), "The impact of gamification on learning and instruction: a systematic review of empirical evidence", Educational Research Review, Vol. 30, p. 100326.

Zichermann, G. and Cunningham, C. (2011), Gamification by Design: Implementing Game Mechanics in Web and Mobile Apps, O'Reilly Media, Sebastopol, CA. 
Zichermann, G. and Linder, J. (2010), Game-based Marketing: Inspire Customer Loyalty through Rewards, Challenges, and Contests, John Wiley and Sons, Hoboken, NJ.

Zyda, M. (2005), "From visual simulation to virtual reality to games", Computer, Vol. 38 No. 9, pp. 25-32.

\begin{abstract}
About the authors
Maria Giovina Pasca is a PhD student in Quality, Innovation and Sustainability, Department of Business Studies, University of Roma Tre, Italy. Her research interests focus on total quality management, sustainability, corporate social responsibility, sharing economy and gamification phenomenon applied in several contexts such as transport and tourism. She is member of the Italian Academy of Commodity Science. Maria Giovina Pasca is the corresponding author and can be contacted at: mariagiovina.pasca@uniroma3.it

Maria Francesca Renzi is a full professor in the Department of Business Studies at Roma Tre University. She teaches Quality Management, Corporate Social Responsibility and Quality Systems. Her areas of interest involve quality management in the public and private sectors, service quality, quality and environmental management systems, and corporate social responsibility. In these fields, she has published 92 scientific contributions. She serves as coordinator of many national and international research projects related to TQM diffusion. She is involved in several national committees as quality assessor. She is member of the Italian Academy of Commodity Science.

Laura Di Pietro is an assistant professor, Department of Business Studies, University of Roma Tre, Italy. She holds a PhD in Commodity Science and Quality Management and teaches Corporate Social Responsibility and Quality Management. She is interested in TQM, service innovation and CSR topics applied in different sectors (e.g. cultural heritage and tourism, public services, healthcare, transport). In particular, she is interested in the study of methods and tools to measure customer satisfaction related to innovative services and sustainability. She is involved in many research projects in public and private sector. She is member of the Italian Academy of Commodity Science.

Roberta Guglielmetti Mugion is an assistant professor, Department of Business Studies, University of Roma Tre, Italy. She has a PhD in Commodity Science and is interested in quality management and sustainability applied in the private and public sector, quality in the food sector, quality and innovation, corporate social responsibility and cultural heritage management. In particular, she focuses on citizens' satisfaction. She is coordinator and member of many research projects related to the TQM diffusion and cultural heritage management system. She is part of the Italian Academy of Commodity Science.
\end{abstract}

For instructions on how to order reprints of this article, please visit our website:

www.emeraldgrouppublishing.com/licensing/reprints.htm

Or contact us for further details: permissions@emeraldinsight.com 